\section{Examination of altered common chord usage in modulation within Classical and Romantic period lieds ${ }^{1}$}

\section{Modülasyonda alterasyonlu ortak akor kullanımının Klasik ve Romantik dönem lied örnekleminde incelenmesi}

\author{
Özlem Özaltunoğlu ${ }^{2}$ \\ Gamze Kurtçu ${ }^{3}$
}

Abstract

In diatonic modulation, a common chord is used between the home and destination keys. Modulation made in this way is given names such as "common chord modulation" or "diatonic pivot chord modulation" in different sources. The common chord is the bridge used to transition between keys at the point where modulation takes place. In choosing this bridge, It is widely accepted that the IInd, IVth or VIth degrees of destination key are preferred. In this study; The use of common chords with alteration during modulation is discussed in terms of the prescriptiveness of the Classical period and the stance of the Romantic period against these rules. The lieds selected from the Classical period and the Romantic period were compared in terms of the use of common chords with alteration during modulation. As a sample, 231 lieds selected from Beethoven, Mozart, Reichardt, Zelter, Schubert, Schumann, Brahms, Franz and Jensen were analyzed. In the lieds examined within the scope of the study, it was observed that most of the 3rd of the

\section{Özet}

Diyatonik modülasyonda genellikle, bulunulan ton ve gidilecek ton arasında bir ortak akor kullanılarak yeni tona geçiş yapılır. Bu şekilde yapılan modülasyonlara farklı kaynaklarda, "ortak akor modülasyonu" ya da "diyatonik pivot akor modülasyonu" gibi isimler verilmektedir. Ortak akor, modülasyonun gerçekleştiği noktada, tonlar arası geçişi sağlamak için kullanılan köprüdür. Bu köprünün seçiminde ise gidilecek tonun II., IV . ya da VI. derecelerinin tercih edilmesi yaygin olarak kabul görmektedir. Bu araştırmada; modülasyon sırasında alterasyon içeren ortak akorların kullanımı, Klasik dönemin kuralcılı̆̆1 ve Romantik dönemin bu kurallara karşı duruşu açısından ele alınmıştır. Klasik dönem ve Romantik dönemden seçilmiş liedler modülasyon sırasında alterasyon içeren ortak akorların kullanımı açısından karşılaştırılmıştır. Örneklem olarak Beethoven, Mozart, Reichardt, Zelter, Schubert, Schumann, Brahms, Franz ve Jensen'den seçilmiş 231 lied incelenmiştir. Araştırma kapsamında incelenen liedlerde,

\footnotetext{
${ }^{1}$ Produced from a part of the Proficiency in Art thesis.

2 Assoc. Prof. Dr., Sivas Cumhuriyet University, Faculty of Education, Department of Music Education, ozozaltun@gmail.com (iD) Orcid ID: 0000-0001-5802-5428

3 Res. Asst. Dr., Sivas Cumhuriyet University, Faculty of Education, Department of Music Education, gamzeyuvaci@gmail.com (iD) Orcid ID: 0000-0002-4532-1161
} 

dönem lied örnekleminde incelenmesi. Journal of Human Sciences, 18(3), 450-472. doi:10.14687/jhs.v18i3.6172

common chords used during modulation were altered. This alteration is the most useful tool in both the Classical and Romantic periods. The use of common chords is remarkable in that it does not create a usage difference between Classical and Romantic periods. In terms of the composers of the lieds studied; When looking at the use of alteration in common chords; Brahms uses four different alterations in common chords that prepare the tone during modulation; Beethoven and Jensen, on the other hand, differ from the other composers studied within the scope of the research, in that they include only one type of alteration.

Keywords: Alteration, modulation, common chord, Classical period, Romantic period. modülasyon sırasinda kullanilan ortak akorların en çok 3lülerinin altere edildiği görülmüştür. $\mathrm{Bu}$ alterasyon, hem Klasik hem de Romantik dönemde en kullanışlı araç olarak karşımıza çıkmaktadır. Ortak akorların Klasik ve Romantik dönem arasında bir kullanım farkı oluşturmaması dikkat çekicidir. İncelenen liedlerin bestecileri açısından; ortak akorlarda alterasyon kullanımına bakıldığında; Brahms, modülasyon sirasinda tonu hazırlayan ortak akorlarda dört farklı alterasyonu da kullanmasiyla; Beethoven ve Jensen ise sadece bir tür alterasyona yer vermeleriyle, araştırma kapsamında incelenen diğer bestecilerden farklılaşmaktadırlar.

Anahtar Kelimeler: Alterasyon, modülasyon, ortak akor, Klasik dönem, Romantik dönem.

(Extended English summary is at the end of this document)

\section{Giriş}

Yüzyıllar boyunca yaşanmış olan gelişmeler sonucunda müzikte modülasyon kullanımı ortaya çıkmıştır. Modlar sisteminde, anladığımız şekliyle modülasyon prensibi olmadığını söyleyen Kitson $(1914,259)$, giderek yaygınlaşan Musica Ficta kullanımının, bir modülasyon etkisi olduğunu ve mevcut dizi sisteminde kullanılan aralıkların homojen bir şekilde düzenlenmesi konusunda önemli bir etken olduğunu belirtmektedir. Glareanus'un Yunan modları olmadan armoninin imkânsız olduğunu düşündüğü kilise modlarının 16. yy’a kadar kullanıldığını belirten Hubbard (1930, 88), modülasyonun ortaya çıkışını açıklarken; ilk modlar veya dizi sesleri arasındaki aralıkların sistematik ardışık sıralamalarının kabul edildiğini, daha sonra tonalite dediğimiz notaların dağılım yönteminin öneminin fark edilmeye başlandığını ifade etmektedir. Ancak 17. yy'a kadar müzisyenlerin böyle bir yöntemin sunduğu olanakları büyük ölçüde kavrayamadıklarını; bir ton içerisindeki özellikler ve akorlardaki değiştirici işaretlerin sanatsal kullanımının önemi anlaşılmadan tabii ki modülasyon olmayacağını belirtmektedir.

Hubbard $(1930,90)$, değiştirici işaretlerin kullanılmasıyla çok ince etkiler üretildiğini, ancak modern besteciler tarafindan değerlendirildiğinde bir düzensizlik izleniminin ortaya çıktığını; 18. yy'ın başlarında bestecilerin saf tonalitenin ne içerdiğinin tam olarak farkına vardığını ve bir süre modülasyonu ihtiyatlı biçimde kullanarak uzun boşluklarda tek bir tonda devam etmekten memnun kaldıklarını, bu durumun modülasyonun en az belirgin olduğu dönem olduğunu söylemektedir. Bunu, sistematik olmayandan sistematik olanın kullanımına geçişin dönüm noktası olarak nitelendirmektedir. Uygulandığında, bestecilerin orijinal tondan çok uzaklaşmaktan korktukları için sadece dominant tonu gibi en yakın tonlara geçiş yapıldığını belirtmektedir. Bu yöntem, modern bestecilerin kullanımı ile karşılaştırıldığında çok belirgin bir fark ortaya çıkar. Hubbard $(1930,90)$ modern bestecilerin, modülasyonu sorunsuz ve zarif bir şekilde yapabildiğini, ortak akor kullanmadan bir tondan diğerine geçmekte daha cesur bir tarzları olduğunu ifade ederken, 18. yy bestecilerinin modülasyonu uygulamada zayıf kaldığını söylemenin çok abartılı olacağını dile getirmektedir. J. S. Bach'ın yöntemlerinin, bulunduğu döneme göre, yüzyıl ilerisinde olduğunu, Bach'ın ardından diğer bestecilerin de yavaş yavaş onun ulaştı̆̆ düzeye geldiğini ve sonunda kesin ve açık bir ton dağıllım sistemi oluşturduklarını söylemektedir. 
Özaltunoğlu, Ö., \& Kurtçu, G. (2021). Modülasyon sırasında alterasyonlu ortak akor kullanımının Klasik ve Romantik dönem lied örnekleminde incelenmesi. Journal of Human Sciences, 18(3), 450-472. doi:10.14687/jhs.v18i3.6172

\section{Ortak Akor}

Kitson $(1914,260)$, ortak akoru modülasyonun ilk prensibi olarak görmektedir. Diyatonik modülasyonda genellikle bulunulan ton ve gidilecek ton arasinda bir ortak akor kullanilarak yeni tona geçiş yapılır. Bu şekilde yapılan modülasyonlara farklı kaynaklarda, "ortak akor modülasyonu” ya da "diyatonik pivot akor modülasyonu" gibi isimler verilmektedir (Korsakof, 1996; Hubbard, 1930; Rougnon, 1930; Özdemir, 2001; Cangal, 2010; Tutu, 1986; Çelebioğlu, 2013; Özaltunoğlu, 2016). Ortak akor, modülasyonun gerçekleştiği noktada, tonlar arası geçişi sağlamak için kullanılan köprüdür. Bu köprünün seçiminde ise gidilecek tonun II., IV. ya da VI. derecelerinin tercih edilmesi yaygın olarak kabul görmektedir. Dizi derecelerinin ortak akor olarak kullanımı ile ilgili Özdemir (2001, 84); gidilecek tonun II., IV. ve VI. derecelerinin öncelikli olarak kullanılması gerektiğini söylemektedir. Özdemir’in $(2001,84)$ yakın tonlara modülasyon sırasında kullandığı ortak akor örnekleri Şekil 1 ve Şekil 2'de görülmektedir.

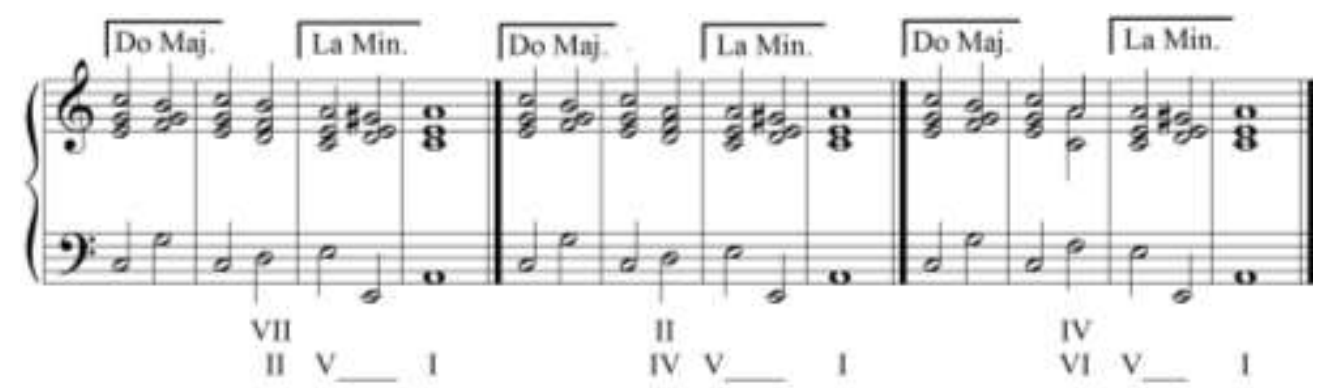

Şekil 1. Ilgili Minör Tona Modülasyon Sirasında Kullanılan Ortak Akorlar (Özdemir, 2001)

Şekil 1'in birinci örneğinde, ilgili minör tona modülasyon sırasında, gidilecek tonun öncelikle II. derecesi kullanılmış ve ardından dominant üzerinde abantı dört-altı akoru ile tonik bağlantısı yapılmıştır. İkinci örnekte aynı modülasyonun gidilecek tonun IV. derecesiyle, üçüncü örnekte ise VI. derecesiyle başladığı görülmektedir.

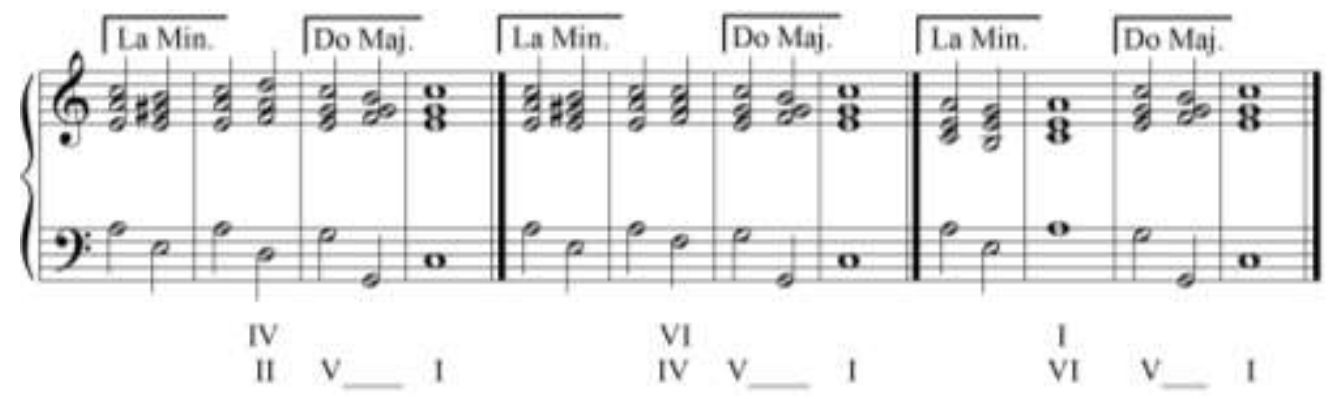

Şekil 2. İlgili Majör Tona Modülasyon Sirasinda Kullamlan Ortak Akorlar (Özdemir 2001)

Şekil 2'nin birinci örneğinde, ilgili majör tona modülasyon sırasında, Şekil 1'de olduğu gibi gidilecek tonun öncelikle II. derecesi kullanılmış ve ardından dominant üzerinde abantı dört-altı akoru ile tonik bağlantısı yapılmıştır. İkinci örnekte aynı modülasyonun gidilecek tonun IV. derecesiyle, üçüncü örnekte ise VI. derecesiyle başladığı görülmektedir.

İki yakın tonalite arasında birden çok ortak akor olduğu zaman, bu akorların hangisinin ortak akor olarak seçilmesi gerektiği sorunu ortaya çıkacaktır.... [Do majörden Sol majöre] modülasyon yaparken (iki tonalite arasında dört tane ortak akor bulunduğu halde) Sol majörün S akorunun ortak alındığını göreceğiz. Gidilecek tonun S akorunun ortak alınması, gidiş tonalitesinde en kısa yoldan tam kadans yapılmasının sağlanması bakımından iyi olur. Çünkü yeni tonun S akorundan sonra Sp, D ve T akorlarının da kullanılmasıyla daha önceki tonaliteden yeni tonaliteye kolayca geçilmiş olur. Şu halde özet olarak söylemek gerekirse, bir tonaliteden diğer bir tonaliteye modülasyon yapilırken, olanaklar elveriyorsa gidilecek tonalitenin sudominant akoru ortak alınmalıdır (Cangal 2010, 241). 
Özaltunoğlu, Ö., \& Kurtçu, G. (2021). Modülasyon sırasında alterasyonlu ortak akor kullanımının Klasik ve Romantik dönem lied örnekleminde incelenmesi. Journal of Human Sciences, 18(3), 450-472. doi:10.14687/ihs.v18i3.6172

Ortak akor genel olarak, bulunulan ve gidilen tonda aynı özelliklere sahip olan bir akorun modülasyon sırasında bir köprü olarak kullanılması şeklinde tanımlanmaktadır. Tutu (1986) ve Rougnon (1930) ortak akor kullanarak modülasyon yapmanın, en sık ve en iyi yöntemlerden biri olduğunu belirtmektedir. Dizi derecelerinin ortak akor olarak kullanımı hakkında Özdemir (2001), gidilecek tonda II., IV. ve VI. derecelerin öncelikli olarak kullanılması gerektiğini belirtirken; Cangal (2010), gidilecek tonun IV. derecesinin ortak akor olarak seçilmesi gerektiğini belirtmektedir. Çelebioğlu (2013) ise diyez yönünde yapılan diyatonik modülasyonlarda, bulunulan tondan III., V. ve VII. derece akorlanı ile çıkıldığında, gidilecek tonun IV., VI. veya II. derece akorlarının elde edileceğini; bemol yönündeki modülasyonlarda ise IV. derece akoru ile tondan çıkıldığında, gidilecek tonun V., III. veya VII. derecelerinin elde edileceğini belirtmektedir.

\section{Altere Edilmiş Ortak Akor}

Alterasyon'un sözlük anlamı: Değişme, Değiştirme'dir. Müzikteki anlamı da bir tonaliteye ait bir akorun bazı seslerinin kromatik inici veya çıkıcı hareketle değiştirilerek kullanılmasıdır (Özdemir, 2001, 95). Bazı eserler, bulundukları tona ait olmayan yabanc1 sesler içermektedir. Donanıma ait olmayan bu yabancı sesler kısa süreli kullanılıp tekrar kaybolurlar. Modülasyona yol açmayan bu durum, değiştirilmiş yani altere edilmiş ses olarak düşünülür. Bulunulan tona göre "ton dışı" olarak nitelendirilen pek çok yabancı ses modülasyona yer vermeden açıklanabilir. Eser bu düşünce ile armonize edilir.

Cutter'e $(1902,204)$ göre; altere akor kromatik olduğu tonun esas derecesine bağlanmak ister. Bir dizinin majör veya minör herhangi bir derecesi kromatik olarak değiştirilebilir. Bu değişikliklerin bazıları akora yabancı sesler yani akor dışı sesler gibi geçiş seslerinden kaynaklanırken, diğerleri akorun etkisini arttırmak için yapılan değişikliklerdir. Akorun etkisini artırmak için yapılan değişikliklere örnek olarak, II. derece 7 linin dominanta veya toniğe doğru olan doğal eğilimi, majör tonlarda artar. Eğer bu alterasyon II. derecenin beşlisinin pestleştirilmesi ile yapıllyorsa akor daha gergin bir etkiye sahip olur. Cutter (1902, 204); birçok akorun, sadece eserdeki kullanım yeri, hızı ve nüansı gibi faktörlerden dolayı altere akor olarak değerlendirilmekte olduğunu; kromatik bir değişikliğin yavaş bir tempoda zihinde bıraktığı etki ile hızlı bir harekette bıraktığı etkinin farklı olduğunu; bu değişiklikler yavaş tempoda duyulduğunda zihinde modülasyon etkisi uyandırırken; hızlı tempoda alterasyon olarak kabul edildiğini söylemektedir.

Altere edilmiş akorlar genel olarak aradominant akorları, ödünç akorlar, napoliten altılısı, kromatik veya diyatonik hareketlerle elde edilmiş akorlar şeklinde sayllabilmektedir. Modülasyon sırasında akorun; 3lüsünün alterasyonu, 5lisinin alterasyonu, 3lüsünün ve 5lisinin aynı anda alterasyonu, Temel sesinin alterasyonu, Temel sesinin ve 3lüsünün aynı anda alterasyonu, Temel sesinin, 3lüsünün ve 5lisinin ayn anda alterasyonu, 7 lisinin alterasyonu, Temel sesinin ve 7 lisinin aynı anda alterasyonu, 9lusunun alterasyonu, 3lüsünün ve 9lusunun aynı anda alterasyonu yoğun olarak kullanılan alterasyon çeșitleridir.

Cangal'a (2010, 249-250) göre, uzak tonalitelere modülasyon, çıkış ya da gidiş tonalitesindeki alterasyonlu bir akor ortak alınarak yapilır. Ortak alınan alterasyonlu akorun cinsine göre uzak tonalitelere modülasyonlar; "gidis tonalitesinin minör sudominantı ortak alınarak yapılan modülasyonlar", "çıkıs tonalitesinin minör sudominantı ortak alınarak yapulan modülasyonlar", "gidiş tonalitesinin minör dominantı ortak alınarak yapılan modülasyonlar" ve "gidis ya da çıııs tonalitesinin napoliten akoru ortak alnarak yapılan modülasyonlar" olarak dört grupta incelenmektedir. Cangal (2010, 250), iki uzak tonalite arasında gidiş tonalitesinin minör sudominant akorunun ortak olabileceğini söylemektedir. Cangal verdiği örnekte, La majörün minör sudominant akorunun, Do majörün II. derecesi olduğunu ve bu şeklide iki uzak tonalite olan Do majörden La majöre modülasyonun, bu akor ortak alınarak yapılabileceğini belirtmektedir. İki uzak ton olan Do majörden La majöre ya da la minöre yapılan modülasyon Şekil 3’te gösterilmektedir. 


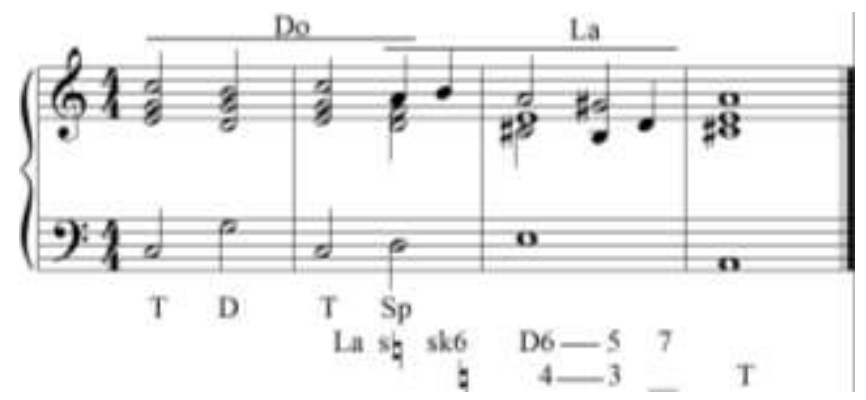

Şekil 3. Alterasyonlu Ortak Akor Örneği (Cangal, 2010: 250)

Şekil 3'te Do Majör'den La Majör'e modülasyon sırasında Do Majörün II. derecesi olan refa-la akorunun, gidilen ton olan La Majör'de altere edilmiş akor olarak kullanıldığı görülmektedir. La Majör'de re-fa\#-la olması beklenen subdominant akorunun üçlüsü pestleştirilerek minör subdominant akoru elde edilmiştir. Şekil 4'te Do majör tonundan uzak bir ton olan Mi bemol majöre modülasyon örneği gösterilmektedir.

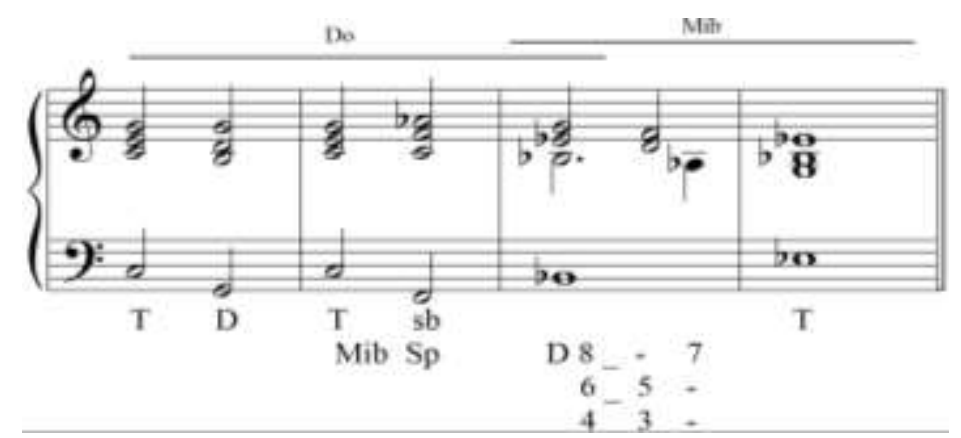

Şekil 4. Alterasyonlu Ortak Akor Örneği Cangal (2010: 252)

Şekil 4'te Do Majör'den Mi bemol Majör'e modülasyon sırasında kullanılan fa-la bemol-do akorunun, bulunulan ton olan Do Majör'de altere edilmiş akor olarak kullanıldığı görülmektedir. Do Majör'de minör subdominant olarak adlandırllan bu akor, Mi bemol Majör'de II. derece akorudur. Do Majör'de fa-la-do olması beklenen subdominant akorunun üçlüsü pestleştirilerek minör subdominant akoru elde edilmiştir.

Modülasyon sırasında kullanılan altere edilmiş ortak akor örnekleri arasında, aradominant akoruna dönüştürülen dizi dereceleri de sayılabilir. Şekil 5'te modülasyon sırasında, gidilecek tonun II. derecesinin dominantı ortak akor olarak kullanılmıştır.

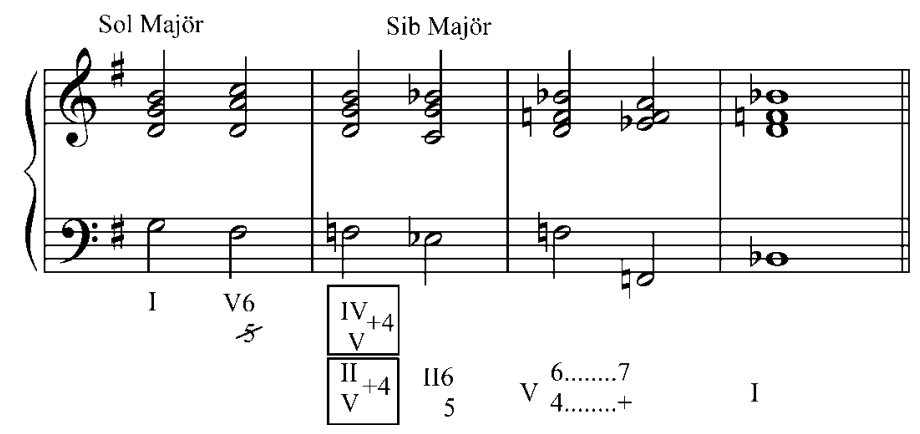

Şekil 5. Alterasyonlu Ortak Akor Örneği - II. Derecenin Dominantı

Şekil 5'te ikinci ölçünün birinci vuruşunda yer alan, Sol majörde subdominant akorunu hazırlayan "sol-si-re-fa" bulunulan tondan Si bemol majöre modülasyon için ortak akor olarak kullanılmıştır. Böylece, bulunulan tonda yani Sol majörde toniğin 7 lisi altere edilerek subdominantın dominant1, gidilen ton yani Si bemol majörde de II. derecenin dominantı ortak akor olarak kullanılmış olur. 


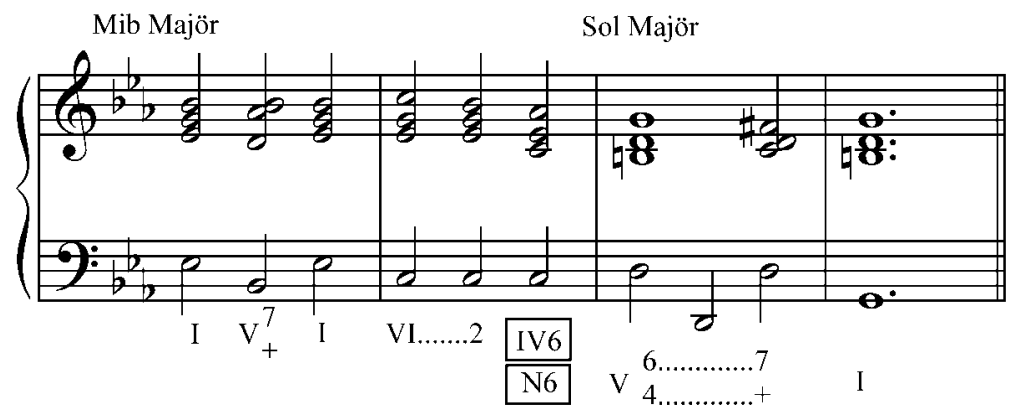

Şekil 6. Alterasyonlu Ortak Akor Örneği - Napoliten Altılsı

Şekil 6'da görülen modülasyon örneğinde, gidilecek tonun napoliten altılı akoru ortak olarak seçilmiştir. Bulunulan tonda yani Mi bemol majörde subdominant olan bu akor, gidilen tonda yani Sol majörde II. derecenin temel ses ve 5lisinin altere edilmesiyle oluşan napoliten altıll akorudur.

Şekil 3 ve 4'te minör subdominant, Şekil 5'te aradominant ve Şekil 6'da napoliten altılısının ortak akor olarak kullanıldığı bu örnekler arttırılabilir. Ortak akor kullanılarak yapılan modülasyonda alterasyon kullanımı, gidilecek tonun duyurulması noktasında dolaylı bir işlem sürecinin oluşmasına yol açar. La majöre modülasyonda adaş minörün subdominantını duyurma, Si bemol Majöre modülasyonda Do minörü hazırlayan dominant 7lisini ortak akor olarak seçme gibi altere kullanımlar, gidilecek tonun duyumunun bir anlığına belirsizleşmesine yol açmaktadır.

\section{Problem}

Modülasyonda altere edilmiş ortak akor kullanımının, Klasik ve Romantik dönem bestecileri açısından çeşitliliği ne düzeydedir? Araştırmanın problem cümlesi olarak belirlenen bu soru; Klasik döneme göre Romantik dönemin alterasyon kullanımı bakımından daha zengin eserler ortaya koyacağı öngörüsüyle irdelenmiştir. Bu araştırmanın amacı; altere edilmiş yani değişime uğramış akorların, bestecinin elinde modülasyon için nasıl bir araca dönüştüğ̈̈nü, bu aracın besteci tarafından ne şekilde kullanıldığını incelemektir. Bu amaçla her iki dönemden seçilen eserler analiz edilerek; içerdikleri modülasyonlar, bu modülasyonlar sırasında kullanılan ortak akorlar ve bu ortak akorlarda görülen alterasyonlar belirlenmiştir.

\section{Evren ve Örneklem}

Araştırmada, modülasyon sırasında kullanılan ortak akorlarda görülen alterasyonların incelenmesi amacıyla Klasik dönem ve Romantik dönemden seçilmiş liedler ele alınmıştır. Bu noktada araştırmanın evrenini piyano vokal müzik eserleri; örneklemini ise Ludwig van Beethoven, Wolfgang Amadeus Mozart, Johann Friedrich Reichardt, Carl Friedrich Zelter, Franz Schubert, Robert Schumann, Johannes Brahms, Robert Franz ve Adolf Jensen'den oluşan dokuz besteci ve bu bestecilere ait 231 adet lied oluşturmaktadır. Araştırmanın örneklemi Tablo 1'de sunulmuştur. 
Özaltunoğlu, Ö., \& Kurtçu, G. (2021). Modülasyon sırasında alterasyonlu ortak akor kullanımının Klasik ve Romantik dönem lied örnekleminde incelenmesi. Journal of Human Sciences, 18(3), 450-472. doi:10.14687/jhs.v18i3.6172

Tablo 1. Örneklemde Yer Alan Eserler

\begin{tabular}{lll}
\hline \hline No & Besteci & Eser Adı \\
\hline $01-010$ & $\begin{array}{l}\text { Ludwig van } \\
(10 \text { lied })\end{array}$ & $\begin{array}{l}\text { Abendlied Unterm Gestirnten Himmel - So Order So - An Die Hofnung - Ich Liebe Dich - An Minna - Der } \\
\text { Liebende - In Questa Tomba Oscura - Elegie - Auf Den Tod Eines Pudels - Des Kriegers Abschied - Der } \\
\text { Jüngling In Der Fremde }\end{array}$ \\
\hline $\begin{array}{l}\text { B1-021 } \\
(11 \text { lied })\end{array}$ & $\begin{array}{l}\text { Wolfgang } \\
\text { Amadeus }\end{array}$ & $\begin{array}{l}\text { Abendempfindung - Mtsytra - Das Lied Der Trennung - An Die Einsamkeit - Ich Würd Auf Meinem Pfad - } \\
\text { Die Betrogene Welt - Aus Dem Franzosischen Des J.J.Rousseau - Seufzer - Ich Würd Auf Meinem Pfad - Die } \\
\text { Entzuckung - An Sie - An Die Bache }\end{array}$ \\
\hline
\end{tabular}

12 Elegies 1. Elegie De Hoffmann - 12 Elegies 2. Regrets D’amour - 12 Elegies 3. Verselets - 12 Elegies 4. Romance - 12 Elegies 5. Romance - 12 Elegies 6. Les Adieux - 12 Elegies 7. A Celle Que Je Ne Veux - 12 Elegies 8. Le Bien Heureux - 12 Elegies 9. Chanson - 12 Elegies 10. İsimsiz - 12 Elegies 11. Chanson - No 1 Selbstbetrug - No 2 Der Musensohn - No 3 Der Neue Amadis - No 4 Wechsellied Zum Tanze - No 5 Verschiedene Empfindungen An Einem Platze - No 6 Der Jüngling - No 7 Der Schmachtende - No 8 Derjager - No 9 Wechsel - No 10 Heidenröslein - No 11 Derabschied - No 12 Weltseele - No 13 Nach.... - No 14 An Die Erwahlte - No 15 Die Schöne Nacht - No 16 Erinnerung - No 17 Neue Liebe Neues Leben - No 18 Neue 022-092 Johann Liebe Neues Leben - No 19 Am Flusse - No 20 Willkommen... - No 21 An Belinden - No 22 Neuere Melodie

(71 lied) Friedrich - No 23 Schafers Klage - No 23 Schafers Klage - No 24 Nahe Des Geliebten - No 25 Frühzeitiger Frühling No 26 Abschied - No 27 Bundeslied - No 28 Bundeslied - No 29 Wonneder Wehniuth - No 30 Dauer İm Wechsel - No 31 Tischlied - No 32 Geistes Gruss - No 33 Zum Neuen Jahr - No 34 Erster Verlust - No 35 Wer Kauft Liebesgötter - No 36 Die Glücklichen Gatten - No 37 Die Glücklichen Gatten - No 38 An Die Entfernte - No 39 Trost İn Thranen - No 40 Notturno - No 41 Sehnsucht - No 42 Sorge - No 43 Anliegen No 44 Vom Berge - No 45 An Mignon - No 46 An Mignon - No 47 Künstlers Morgenlied - No 48 Künstlers Abendlied - No 49 An Den Mond - No 50 Einschrankung - No 51 Maylied - No 52 Mit Einem Gemahlten No 53 Wandrers Nachtlied - No 54 Wandrers Nachtlied - No 55 Jagers Nachtlied - No 56 Rettung - No 57 Vanitas... - No 58 Christel - No 59 Frühlings Orakel - No 60 An Lina

\begin{tabular}{|c|c|c|}
\hline $\begin{array}{l}093-147 \\
(55 \text { lied })\end{array}$ & $\begin{array}{l}\text { Carl Friedrich } \\
\text { Zelter }\end{array}$ & $\begin{array}{l}\text { Z122 No } 1 \text { - Z122 No } 2 \text { - Z122 No } 3 \text { - Z122 No4 - Z122 No5 - Z122 No6 - Z122 No7 - Z122 No8 - Z122 } \\
\text { No } 9 \text { - Z122 No } 10 \text { - Z122 No } 11 \text { - Z122 No } 12 \text { - Z128 No } 1 \text { - Z128 No } 3 \text { - Z128 No - Z128 No } 5 \text { - Z124 No } \\
1 \text { - Z124 No } 2 \text { - Z124 No } 3 \text { - Z124 No } 4 \text { - Z124 No } 5 \text { - Z124 No } 6 \text { - Z124 No } 7 \text { - Z124 No } 8 \text { - Z124 No } 9 \text { - } \\
\text { Z124 No } 10 \text { - Z124 No11 - Z124 No } 12 \text { - Z126 No } 1 \text { - Z126 No } 2 \text { - Z126 No } 3 \text { - Z126 No } 5 \text { - Z126 No } 6 \text { - } \\
\text { Z126 No } 7 \text { - Z126 No } 8 \text { - Z126 No } 9 \text { - Z126 No } 10 \text { - Z126 No } 11 \text { - Z126 No } 12 \text { - Z127 No2 - Z127 No3 - } \\
\text { Z127 No5 - Z127 No6 - Z123 No } 1 \text { - Z123 No } 2 \text { - Z123 No } 3 \text { - Z123 No } 4 \text { - Z123 No } 5 \text { - Z123 No } 6 \text { - Z123 } \\
\text { No } 7 \text { - Z123 No } 8 \text { - Z123 No } 9 \text { - Z123 No } 10 \text { - Z123 No } 11 \text { - Z123 No } 12\end{array}$ \\
\hline $\begin{array}{l}148-162 \\
(15 \text { lied })\end{array}$ & Franz Schubert & $\begin{array}{l}\text { Abendlied No:133 - Abendlied No:190 - Abendlied No:278 - Abends Unter Der Linde No:100 - Abends Unter } \\
\text { Der Linde No:101 - Abendstandchen No:125 - Abendstern No:459 - Abschied No:586 - Abschied No:251 - } \\
\text { Abschied Von Der Harfe No208 - Alles Um Liebe No:104 - Alte Liebe Rostet Nie No:253 - Am Flusse No:418 } \\
\text { - An Den Schlaf No: } 232 \text { - An Den Tod No:326 }\end{array}$ \\
\hline $\begin{array}{l}163-170 \\
(8 \text { lied })\end{array}$ & $\begin{array}{l}\text { Robert } \\
\text { Schumann }\end{array}$ & $\begin{array}{l}\text { Op.48 dichterliebe 1. Im Wunderschönen Monat Mai - 2. Aus Meinen Tranen Spriessen - 3. Die Rose Die Lilie } \\
\text { Die Taube - 5. Ich Will Meine Seele Tauchen - 7. Ich Grolle Nicht }-9 \ldots \ldots-10 \ldots-11 \ldots \ldots\end{array}$ \\
\hline $\begin{array}{l}171-211 \\
(41 \text { lied })\end{array}$ & $\begin{array}{l}\text { Johannes } \\
\text { Brahms }\end{array}$ & $\begin{array}{l}\text { WoO } 33 \text { No: } 1 \text { - No: } 2 \text { - No: } 3 \text { - No: } 4 \text { - No: } 5 \text { - No: } 6 \text { - No: } 7 \text { - No: } 8 \text { - No: } 9 \text { - No: } 10 \text { - No: } 11 \text { - No: } 12 \text { - No: } \\
13 \text { - No: } 14 \text { - No: } 15 \text { - No: } 16 \text { - No: } 17 \text { - No: } 18 \text { - No: } 19 \text { - No: } 20 \text { - No: } 21 \text { - No: } 22 \text { - No: } 23 \text { - No: } 24 \text { - No: } 25 \\
\text { - No: } 26 \text { - No: } 27 \text { - No: } 28 \text { - No: } 29 \text { - No: } 30 \text { - No: } 31 \text { - No: } 32 \text { - No: } 33 \text { - No: } 34 \text { - No: } 36 \text { - No: } 37 \text { - No: } 38 \text { - } \\
\text { No: } 39 \text { - No: } 40 \text { - No: } 41 \text { - No: } 42\end{array}$ \\
\hline $\begin{array}{l}212-221 \\
(10 \text { lied })\end{array}$ & Robert Franz & $\begin{array}{l}\text { His Coming - Out Of My Soul's Great Sadness - Lassie With The Lips So Rosy - Das Ist Ein Brausen Und } \\
\text { Heulen - Bitte - Widmung - Willkommen, Mein Wald - Die Lotosblume }\end{array}$ \\
\hline $\begin{array}{l}221-231 \\
(10 \text { lied })\end{array}$ & Adolf Jensen & $\begin{array}{l}\text { Press Thy Cheek Against Mine Own - A Breath Of Spring - From Slumber Awaken - Murmuring Breezes - } \\
\text { Where Flows The Bright River - O Stay Thy Passing, Golden Moments - My Heart's In The Highlands - When } \\
\text { Through The Piazzetta - Row Gently Here, My Gondolier - Lullaby Of An Infant Chief }\end{array}$ \\
\hline
\end{tabular}

\section{Bulgular}

Klasik ve Romantik dönem lied örnekleminde, modülasyon sırasında alterasyonlu ortak akor kullanımı incelendiğinde, örneklemde yer alan 231 eserin 43'ünde 64 kez ortak akorun altere edildiği görülmektedir. Bu alterasyonlar; akorun "3lüsünün" alterasyonu, "3lüsünün ve 5lisinin" aynı anda alterasyonu, "temel sesinin" alterasyonu, "temel sesinin ve 7lisinin" aynı anda alterasyonu, "5lisinin" alterasyonu, "7lisinin" alterasyonu, "3lüsünün ve 9lusunun" aynı anda alterasyonu şeklinde yedi gruba ayrilmaktadır. Tablo 2'de bu alterasyonların hangi dönemde, hangi besteciler tarafindan, ne sıklıkta kullanıldığ gösterilmiştir. 
Özaltunoğlu, Ö., \& Kurtçu, G. (2021). Modülasyon sırasında alterasyonlu ortak akor kullanımının Klasik ve Romantik dönem lied örnekleminde incelenmesi. Journal of Human Sciences, 18(3), 450-472. doi:10.14687/jhs.v18i3.6172

Tablo 2. Modülasyon Sirasinda Kullanilan Ortak. Akorlarda Yer Alan Alterasyonlar

\begin{tabular}{|c|c|c|c|c|c|c|c|c|c|c|}
\hline Dönem & & Klasik & önem & & & Rom & intik Dör & & & $f$ \\
\hline Besteci & Beethoven & Mozart & Reichardt & Zelter & Schubert & Schumann & Brahms & Franz & Jensen & J \\
\hline $\begin{array}{l}\text { İncelenen } \\
\text { Eser Say1s1 }\end{array}$ & 10 & 11 & 71 & 55 & 15 & 8 & 41 & 10 & 10 & 231 \\
\hline 3lünün Alterasyonu & 2 & 5 & 10 & 7 & 2 & 6 & 6 & 7 & 2 & 47 \\
\hline $\begin{array}{l}\text { Temel Sesin } \\
\text { Alterasyonu }\end{array}$ & - & - & 3 & - & 1 & - & 1 & 1 & - & 6 \\
\hline $\begin{array}{l}\text { 3lünün ve 5linin } \\
\text { Alterasyonu }\end{array}$ & - & - & - & 2 & - & - & 2 & - & - & 4 \\
\hline 7linin Alterasyonu & - & 1 & - & - & - & 1 & 1 & - & - & 3 \\
\hline 5linin Alterasyonu & - & - & 1 & 1 & - & - & - & - & - & 2 \\
\hline $\begin{array}{l}\text { Temel Sesin ve } 7 \text { linin } \\
\text { Alterasyonu }\end{array}$ & - & 1 & - & - & - & - & - & - & - & 1 \\
\hline $\begin{array}{l}\text { 3lünün ve 9lunun } \\
\text { Alterasyonu }\end{array}$ & - & - & - & - & - & 1 & - & - & - & 1 \\
\hline $\begin{array}{l}\text { Toplam Alterasyon } \\
\text { Sayis1 }\end{array}$ & 2 & 7 & 14 & 10 & 3 & 8 & 10 & 8 & 2 & 64 \\
\hline $\begin{array}{l}\text { Dönemlere Göre } \\
\text { Alterasyon Sayıs1 }\end{array}$ & & & & & & & 31 & & & 64 \\
\hline
\end{tabular}

Modülasyonu hazırlayan ortak akorda; en çok değişikliğe uğrayan ses 3lüdür. Bu değişim farklı eserlerde $47 \mathrm{kez}$ kullanılmıştır. Diğer alterasyonların toplam sayısı ise 17'dir. Temel sesin alterasyonu 6 kere, 3lünün ve 5linin aynı anda alterasyonu 4 kere, 7 linin alterasyonu 3 kere, 5 linin alterasyonu 2 kere, temel sesin ve 7linin aynı anda, 3lünün ve 9lunun aynı anda alterasyonları ise sadece 1 kere kullanılmıştır. Grafik 1'de, altere edilmiş ortak akor kullanımının besteciler açısından ne düzeyde çeşitlendiği gösterilmiştir.

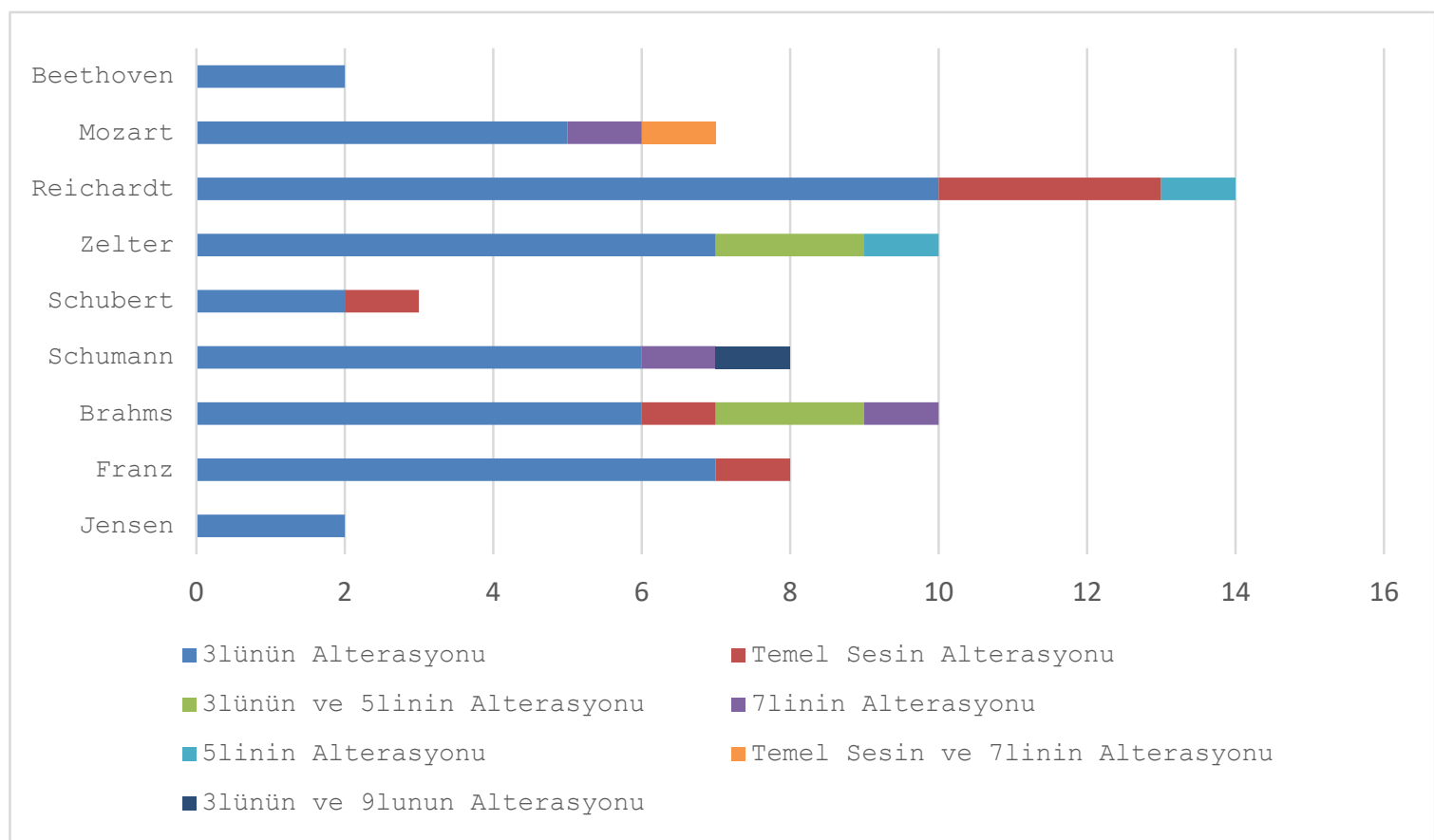

Grafik 1. Altere Edilmiş Ortak Akorlarn Bestecilere Göre Dă̆llım

Grafik 1'e görüldügü gibi; Johann Friedrich Reichardt, Carl Friedrich Zelter ve Johannes Brahms altere edilmiş ortak akoru diğer bestecilere göre çok daha fazla sayıda kullanmaktadır. Reichardt 14, Brahms ve Zelter ise 10'ar tane alterasyona yer vermiştir.

Reichardt'ın bu 14 alterasyonun 10 tanesini akorun 3lüsünde, 3 tanesini akorun temel sesinde, 1 tanesini ise 5lisinde kullandığ1; Zelter'in bu 10 alterasyonun 7 tanesini akorun 3lüsünde, 
Özaltunoğlu, Ö., \& Kurtçu, G. (2021). Modülasyon sırasında alterasyonlu ortak akor kullanımının Klasik ve Romantik dönem lied örnekleminde incelenmesi. Journal of Human Sciences, 18(3), 450-472. doi:10.14687/jhs.v18i3.6172

2 tanesini akorun 3lüsü ve 5lisinde, 1 tanesini ise 5lisinde kullandığı; her iki bestecinin de incelenen eserlerinde altere edilmiş ortak akorlara üç farklı şekilde yer verdiği görülmüştür.

Brahms'in kullandığı alterasyonlar, araştırma kapsamında ulaşılan yedi alterasyon çeşidinden dördünü içermesi bakımından diğer bestecilerden farklılaşmaktadır. İncelenen eserlerde Brahms, modülasyon için kullandığı ortak akorun 3lüsünü 6 kere, 3lü ve 5lisini 2 kere, temel sesini 1 kere ve son olarak sadece 7 lisini 1 kere altere etmiştir.

Modülasyon sırasında altere edilmiş ortak akora; Robert Schumann ve Robert Franz'in incelenen eserlerinde 8'er kez, Wolfgang Amadeus Mozart'in incelenen eserlerinde 7 kez yer verdiği görülmektedir. Schumann 3lünün alterasyonunu 6 kere, 7linin alterasyonu, 3lünün ve 9lunun alterasyonunu 1'er kere kullanmıştır. Franz, incelenen eserlerinde 1 akorda temel sesin alterasyonu, diğer 7 akorda da 3lünün alterasyonu olmak üzere 2 farklı alterasyona yer vermektedir. Mozart, modülasyon için kullandığı ortak akorun 3lüsünü 5 kere, 7 lisini 1 kere, temel sesini ve 7lisini 1 kere altere etmiştir.

Son olarak Franz Schubert, Ludwig van Beethoven ve Adolf Jensen'in modülasyon sırasında altere edilmiş ortak akor kullanımına bakıldığında; Schubert'in incelenen eserlerinde 3lünün alterasyonunu 2 kere, temel sesin alterasyonunu 1 kere olmak üzere 2 farklı alterasyona yer verdiği görülmüştür. Beethoven ve Jensen ise incelenen eserlerinde sadece 3lünün alterasyonunu 2'şer kez kullanmışlar, modülasyon sırasında kullanılan ortak akorda diğer alterasyonlara yer vermemişlerdir. Grafik 2'de modülasyon sırasında kullanılan altere edilmiş ortak akorların dağılımı, Klasik dönem ve Romantik dönemdeki kullanımları karşılaştırılarak verilmiştir.

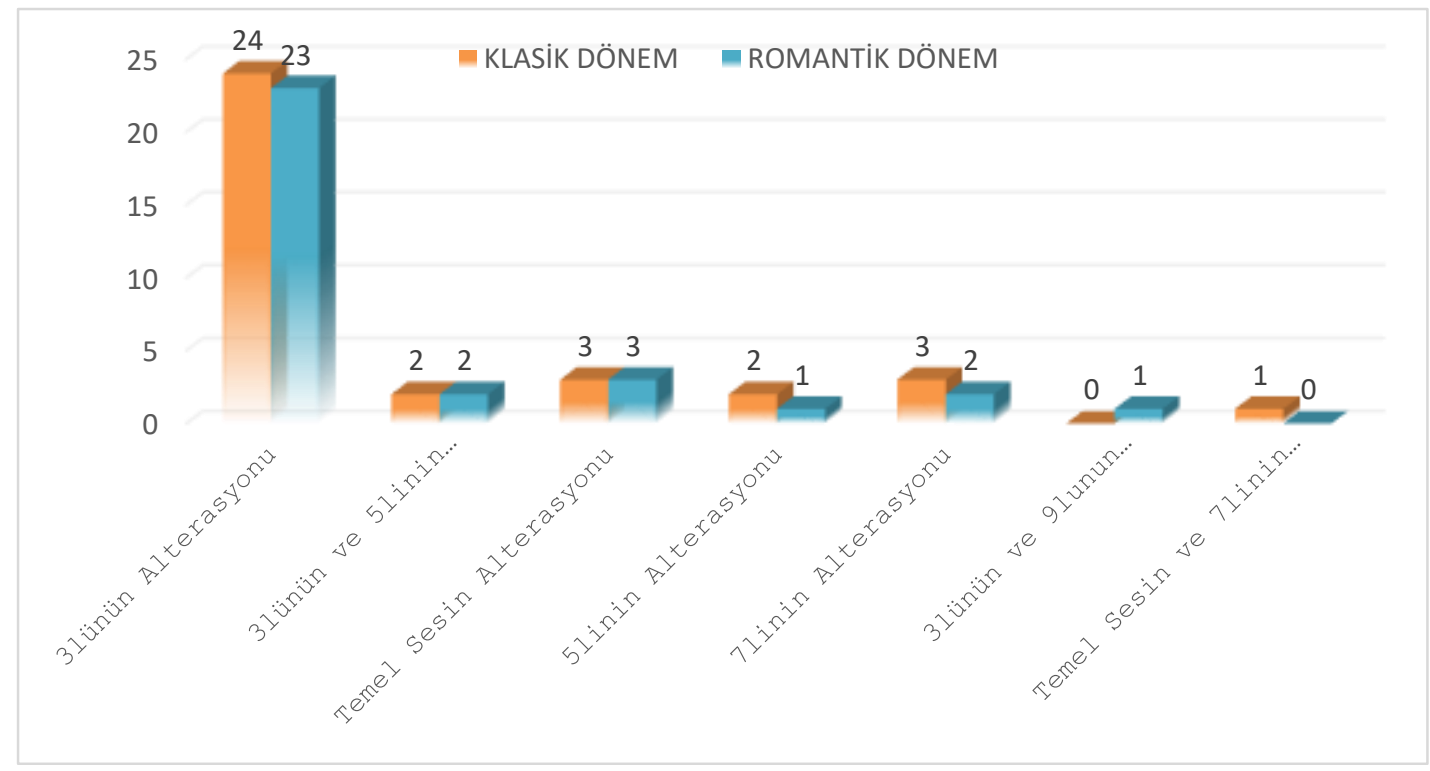

Grafik 2. Altere Edilmiş Ortak. Akorlarn Klasik ve Romantik Dönemde Kullanım Sıkluğ

Grafik 2 incelendiğinde; 3lüsü altere edilmiş ortak akor kullanımının dönemler arasında belirgin bir fark oluşturmadığ1, her iki dönemde de en çok tercih edilen alterasyon olduğu görülmektedir. Benzer şekilde, temel sesi altere edilmiş, 7lisi altere edilmiş, 3lüsü ve 5lisi altere edilmiş, 5lisi altere edilmiş ortak akor kullanımında da dönemler arasında belirgin bir farklılık oluşmamaktadır. Klasik dönemde 3lüsü ve 9lusu altere edilmiş ortak akor; Romantik dönemde de temel sesi ve 7 lisi altere edilmiş ortak akor kullanımının tercih edilmediği görülmektedir. İlerleyen başlıklarda, modülasyon sırasında kullanılan ortak akorlar içerdikleri alterasyonlar bakımından gruplandırılarak, örnek eserler üzerinde gösterilmiştir. 
Özaltunoğlu, Ö., \& Kurtçu, G. (2021). Modülasyon sırasında alterasyonlu ortak akor kullanımının Klasik ve Romantik dönem lied örnekleminde incelenmesi. Journal of Human Sciences, 18(3), 450-472. doi:10.14687/jhs.v18i3.6172

\section{3lüsü Altere Edilmiş Ortak Akor Kullanımı}

Tablo 3’te, modülasyon sırasında kullanılan ortak akorlarda "3lünün alterasyonunu” içeren eserler; besteci isimleri, eser sayıları, modülasyondaki görevleri, eser numaraları ve altere edilmiş ortak akorun eserdeki kullanım sıklı̆̆1 yazılarak gösterilmiştir.

Tablo 3. Modülasyon Sirasında Kullanılan Ortak. Akorlarda 3lünün Alterasyonu

\begin{tabular}{|c|c|c|c|c|c|}
\hline Besteci & $\begin{array}{c}\text { Eser } \\
\text { Sayı1s1 }\end{array}$ & Bulunulan Tonda Ortak Akorun Görevi & Gidilen Tonda Ortak Akorun Görevi & $\begin{array}{c}\text { Eser } \\
\text { No }\end{array}$ & $f$ \\
\hline \multirow{2}{*}{$\begin{array}{l}\text { Ludwig van } \\
\text { Beethoven }\end{array}$} & \multirow{2}{*}{1} & I. derece & VI. derece (3lünün alterasyonu) & \multirow{2}{*}{003} & 1 \\
\hline & & I. derece & IV. derece (3lünün alterasyonu) & & 1 \\
\hline \multirow{5}{*}{$\begin{array}{l}\text { Wolfgang } \\
\text { Amadeus } \\
\text { Mozart }\end{array}$} & \multirow{5}{*}{5} & V. derece (3lünün alterasyonu) & VI. derece & 011 & 1 \\
\hline & & V. derece & I. derece (3lünün alterasyonu) & 017 & 1 \\
\hline & & I. derece (3lünün alterasyonu) & III. derece (3lünün alterasyonu) & 018 & 1 \\
\hline & & V. derece & III. derece (3lünün alterasyonu) & 019 & 1 \\
\hline & & V. derece & III. derece (3lünün alterasyonu) & 020 & 1 \\
\hline \multirow{10}{*}{$\begin{array}{l}\text { Johann } \\
\text { Friedrich } \\
\text { Reichardt }\end{array}$} & \multirow{10}{*}{9} & II. derece (3lünün alterasyonu) & VI. derece (3lünün alterasyonu) & 026 & 1 \\
\hline & & II. derece (3lünün alterasyonu) & VI. derece (3lünün alterasyonu) & 035 & 1 \\
\hline & & I. derece & II. derece (3lünün alterasyonu) & 048 & 1 \\
\hline & & V. derece & II. derece (3lünün alterasyonu) & 051 & 1 \\
\hline & & I. derece (3lünün alterasyonu) & IV. derece (3lünün alterasyonu) & \multirow{2}{*}{053} & 1 \\
\hline & & I. derece & II. derece (3lünün alterasyonu) & & 1 \\
\hline & & I. derece & IV. derece (3lünün alterasyonu) & 062 & 1 \\
\hline & & II. derece (3lünün alterasyonu) & VI. derece (3lünün alterasyonu) & 068 & 1 \\
\hline & & V. derece & II. derece (3lünün alterasyonu) & 076 & 1 \\
\hline & & VI. derece & V. derece (3lünün alterasyonu) & 085 & 1 \\
\hline \multirow{6}{*}{$\begin{array}{l}\text { Carl Friedrich } \\
\text { Zelter }\end{array}$} & \multirow{6}{*}{6} & III. derece (3lünün alterasyonu) & I. derece (3lünün alterasyonu) & 101 & 1 \\
\hline & & I. derece (3lünün alterasyonu) & III. derece (3lünün alterasyonu) & 105 & 1 \\
\hline & & V. derece & III. derece (3lünün alterasyonu) & 127 & 1 \\
\hline & & III. derece (3lünün alterasyonu) & II. derece (3lünün alterasyonu) & 130 & 1 \\
\hline & & IV. derece (3lünün alterasyonu) & II. derece (3lünün alterasyonu) & 136 & 1 \\
\hline & & VI. derece (3lünün alterasyonu) & II. derece (3lünün alterasyonu) & 144 & 2 \\
\hline Franz Schubert & 1 & II. derece & IV. derece (3lünün alterasyonu) & 154 & 2 \\
\hline \multirow{4}{*}{$\begin{array}{l}\text { Robert } \\
\text { Schumann }\end{array}$} & \multirow{4}{*}{3} & V. derece (3lünün alterasyonu) & IV. derece & \multirow{2}{*}{163} & 2 \\
\hline & & VI. derece (3lünün alterasyonu) & IV. derece (3lünün alterasyonu) & & 2 \\
\hline & & V. derece & II. derece (3lünün alterasyonu) & 168 & 1 \\
\hline & & I. derece & VI. derece (3lünün alterasyonu) & 170 & 1 \\
\hline \multirow{3}{*}{$\begin{array}{l}\text { Johannes } \\
\text { Brahms }\end{array}$} & \multirow{3}{*}{3} & V. derece & II. derece (3lünün alterasyonu) & 194 & 2 \\
\hline & & V. derece & II. derece (3lünün alterasyonu) & 195 & 2 \\
\hline & & V. derece & III. derece (3lünün alterasyonu) & 206 & 2 \\
\hline \multirow{3}{*}{ Robert Franz } & \multirow{3}{*}{3} & IV. derece & II. derece (3lünün alterasyonu) & 213 & 3 \\
\hline & & VII. derece & III. derece (3lünün alterasyonu) & 217 & 1 \\
\hline & & VI. derece (3lünün alterasyonu) & II. derece (3lünün alterasyonu) & 219 & 3 \\
\hline \multirow{2}{*}{ Adolf Jensen } & \multirow{2}{*}{2} & V. derece & II. derece (3lünün alterasyonu) & 225 & 1 \\
\hline & & V. derece & II. derece (3lünün alterasyonu) & 231 & 1 \\
\hline Eser Say1s1 & 33 & & & Akor Sayıs1 & 47 \\
\hline
\end{tabular}

Tablo 3’te görüldügü gibi örneklemde yer alan 231 eserin 33’ünde; modülasyon sirasinda kullanılan ortak akor, "3lüsü" altere edilerek kullanılmıştır. Bu alterasyonu; Ludwig van Beethoven'in incelenen eserlerinin 1'inde 2 kez, Wolfgang Amadeus Mozart'in incelenen eserlerinin 
Özaltunoğlu, Ö., \& Kurtçu, G. (2021). Modülasyon sırasında alterasyonlu ortak akor kullanımının Klasik ve Romantik dönem lied örnekleminde incelenmesi. Journal of Human Sciences, 18(3), 450-472. doi:10.14687/jhs.v18i3.6172

5 'inde 5 kez, Johann Friedrich Reichardt'in incelenen eserlerinin 9'unda 10 kez, Carl Friedrich Zelter'in incelenen eserlerinin 6'sinda 7 kez, Franz Schubert'in incelenen eserlerinin 1'inde 2 kez, Robert Schumann'ın incelenen eserlerinin 3'ünde 6 kez, Johannes Brahms'ın incelenen eserlerinin 3’ünde $6 \mathrm{kez}$, Robert Franz'in incelenen eserlerinin 3'ünde $7 \mathrm{kez}$, Adolf Jensen'in incelenen eserlerinin 2'sinde 2 kez kullandığ1 görülmektedir. Araştırma kapsamında incelenen liedlerde modülasyon sırasında kullanılan ortak akorlarda 3lünün alterasyonunu en çok kullanmayı tercih eden besteci Johann Friedrich Reichardt iken en az sayıda kullanan besteci Ludwig van Beethoven, Franz Schubert ve Adolf Jensen'dir.

Bu akor; 22 eserde gidilecek tona göre; 2 eserde bulunulan tona göre, 12 eserde de hem bulunulan ton hem de gidilecek tona göre alterasyon içermektektedir. Besteciler modülasyonu hazırlayan ortak akordaki bu alterasyonu, daha çok gidilecek ton açısından ele almakta, her iki tonda ya da sadece bulunulan tonda 3lüsü altere edilmiş ortak akor kullanımı daha az tercih edilmektedir. Dizi derecelerine göre 3lüsü altere edilmiş ortak akorların dağılımı, akorun modülasyondaki yeri ve kullanım sıklığına ilişkin bilgiler Tablo 4'te gösterilmiştir.

Tablo 4. Dį̨i Derecelerine Göre 3lüsü Altere Edilmiş Ortak Akorlarn Dă̆glımı

\begin{tabular}{lcc}
\hline \multirow{2}{*}{ Dizi Derecesi } & \multicolumn{2}{c}{ Modülasyondaki Yeri } \\
\cline { 2 - 3 } & $\begin{array}{c}\text { Bulunulan tonda } \\
\text { I. derece akoru }\end{array}$ & $\begin{array}{c}\text { Gidilecek tonda } \\
f\end{array}$ \\
\hline II. derece akoru & 3 & 2 \\
\hline III. derece akoru & 3 & 21 \\
\hline IV. derece akoru & 2 & 8 \\
\hline V. derece akoru & 1 & 7 \\
\hline VI. derece akoru & 3 & 5 \\
\hline \hline
\end{tabular}

“3lünün alterasyonu” akorun kimliğini değiştirmesi açısından önem taşımaktadır. Majör bir eserde akorun 3lüsü pestleştirilerek minör bir duyum sağlanırken, minör bir akor üzerinde akorun 3lüsü tizleştirilerek majör bir duyum elde edilir. Aşağıdaki açıklamalarda 3lüsü altere edilmiş ortak akorun, gidilecek tonda "dominant dominant", "VI. derecenin dominantt", "majör/minör subdominant" ve "II. derecenin dominantı" olarak kullanıldığ1 Franz ve Reichardt'tan seçilmiş dört eser örneklenmiştir.

\section{1üsü Altere Edilmiş Ortak Akorun Gidilecek Tonda Dominant Dominantı Olarak Kullanımı}

Tablo 4'e bakıldığında; incelenen eserlerde, modülasyon sırasında kullanılan ortak akorun 3lüsü, gidilecek tonun II. derece akorunda $21 \mathrm{kez}$ altere edilmiştir. II. derecenin 3lüsünün alterasyonu "dominant dominantı" olarak adlandırılan aradominant akorudur. Bu noktada 3lünün alterasyonu ile elde edilmek istenen etkinin çoğunlukla gidilecek tona varmadan onun dominantı olan tonu hissettirmek olduğu söylenebilir. II. derecede 3lünün alterasyonuna örnek olarak Şekil 7'de örneklem içerisinde 219 numara olarak yer alan Robert Franz'in Willkommen, Mein Wald adlı eserinin 9-16. ölçüleri verilmiştir. Eserin 14. ölçüsünde, La bemol majör tonundan Mi bemol majör tonuna modülasyon sırasında ortak akor olarak seçilen derecenin 3lüsünün tizleştirilerek kullanıldığ1 görülmektedir. Aynı ortak akor eserin 35. ve 56. ölçülerinde de kullanılmıştır. 
Özaltunoğlu, Ö., \& Kurtçu, G. (2021). Modülasyon sırasında alterasyonlu ortak akor kullanımının Klasik ve Romantik dönem lied örnekleminde incelenmesi. Journal of Human Sciences, 18(3), 450-472. doi:10.14687/ihs.v18i3.6172

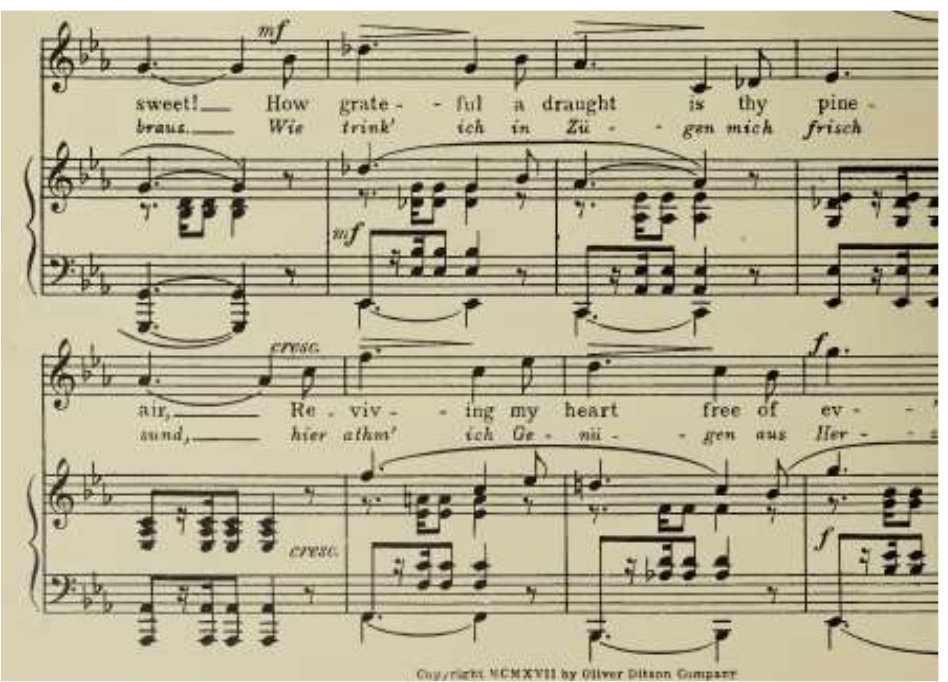

Şekil 7. II. Derecede 3lünün Alterasyonu (Franz- Willkommen, Mein Wald, 9-16. ölçüler)

La bemol majörden mi bemol majöre modülasyon sirasında ortak olarak kullanılan fa-la natürel-do-mib akoru, bulunulan tonda II. derecenin dominantı, gidilecek tonda ise V. derecenin dominantıdır. Mi bemol majör tonuna modülasyon yapılırken, II. derece 7li akorunun 3lüsünün tizleştirilerek kullanılmasıyla bir anlığına da olsa si bemol majör tonunun duyurulduğu, ardından re natürel ve la bemol sesleriyle mi bemol majör tonunun otantik kadansının kullanıldığ1 görülmektedir.

\section{3lüsü Altere Edilmiş Ortak Akorun Gidilecek Tonda VI. Derecenin Dominantı Olarak Kullanımı}

Tablo 4'te, gidilecek tonun III. derecesinde bu alterasyonun 8 kez kullanıldı̆̆1 görülmektedir. III. derecenin 3lüsünün alterasyonu "VI. derecenin dominantı" olarak adlandırılan aradominant akorudur. Bu noktada 3lünün alterasyonu ile elde edilmek istenen etkinin çoğunlukla gidilecek tona varmadan onun ilgili minör tonunu hissettirmek olduğu söylenebilir. III. derecede 3lünün alterasyonuna örnek olarak Şekil 8'de örneklem içerisinde 217 numara olarak yer alan Robert Franz’ın Bitte adlı eserinin 6-16. ölçüleri verilmiştir. Eserin 13. ölçüsünde, Re bemol majör tonundan La bemol majör tonuna modülasyon sırasında ortak akor olarak seçilen derecenin 3lüsünün tizleştirilerek kullanıldığ1 görülmektedir.

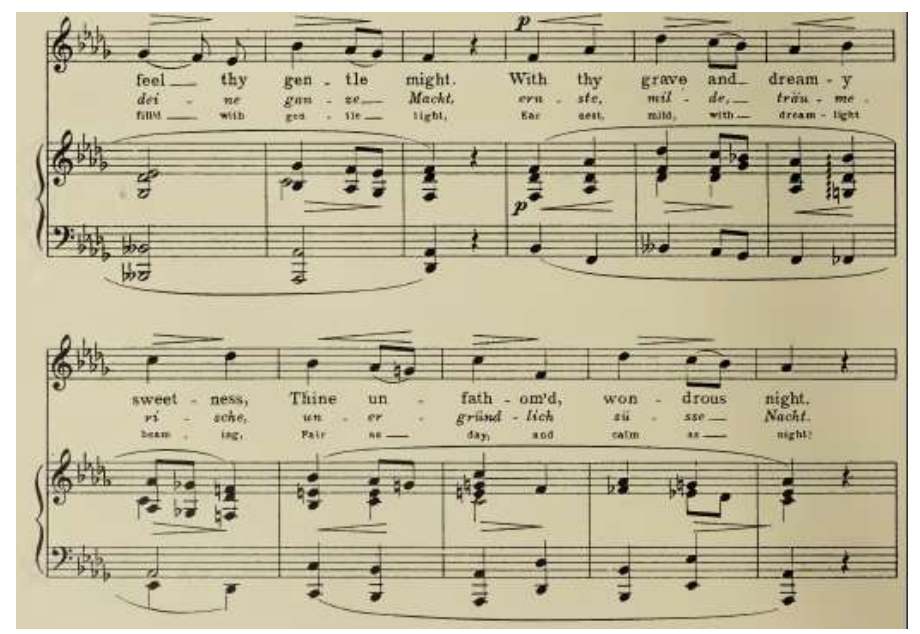

Şekil 8. III. Derecede 3lünün Alterasyonu (Franz - Bitte, 6-16. ölçüler)

Re bemol majörden la bemol majöre modülasyon sırasında ortak olarak kullanılan do-mi natürel-sol natürel-sib akoru, bulunulan tonda III. derecenin dominant1, gidilecek tonda ise VI. derecenin dominantıdır. La bemol majör tonuna modülasyon yapılırken, III. derece 7li akorunun 
Özaltunoğlu, Ö., \& Kurtçu, G. (2021). Modülasyon sırasında alterasyonlu ortak akor kullanımının Klasik ve Romantik dönem lied örnekleminde incelenmesi. Journal of Human Sciences, 18(3), 450-472. doi:10.14687/jhs.v18i3.6172

3lüsünün tizleştirilerek kullanılmasıyla bir anlığına da olsa akraba minör ton olan fa minör tonunun duyurulduğu, ardından mi bemol sesinin eklenmesiyle La bemol majör tonunun otantik kadansının kullanıldığ1 görülmektedir.

\section{3lüsü Altere Edilmiş Ortak Akorun Gidilecek Tonda Minör Subdominant Olarak Kullanımı}

Tablo 4'te, gidilecek tonun IV. derecesinde bu alterasyonun 7 kez kullanıldığ1 görülmektedir. IV. derecenin 3lüsünün alterasyonu "majör/minör subdominant" olarak adlandırılır. Bu noktada 3lünün alterasyonu ile elde edilmek istenen etkinin çoğunlukla gidilecek tona varmadan onun adaş majör/minör tonunu hissettirmek olduğu söylenebilir. IV. derecede 3lünün alterasyonuna örnek olarak Şekil 9'da örneklem içerisinde 053 numara olarak yer alan Johann Friedrich Reichardt'in An Belinden adlı eserinin ilk 5 ölçüsü verilmiştir. Eserin 3. ölçüsünde, La majörden Mi majöre modülasyon sirasında ortak akor olarak seçilen derecenin 3lüsünün pestleştirilerek kullanıldığı görülmektedir.

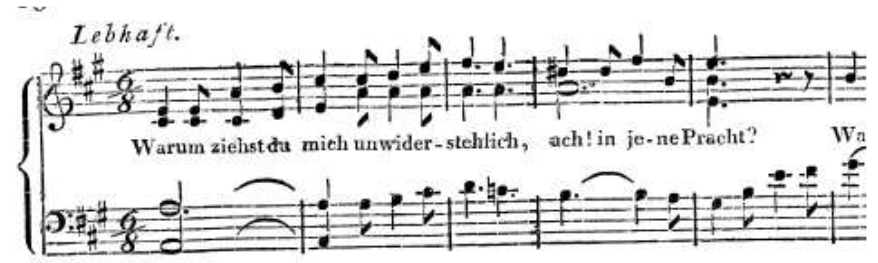

Şekil 9. IV. Derecede 3lünün Alterasyonu (Reichardt - An Belinden, 1-5. ölgüler)

La majörden mi majöre modülasyon sırasında ortak olarak kullanılan la-do natürel-mi akoru, bulunulan majör tonda "minör tonik", gidilecek majör tonda ise "minör subdominant" akorudur. Mi majör tonuna modülasyon yapılırken, IV. derece akorunun 3lüsünün pestleştirilerek kullanılmasıyla bir anlığına da olsa adaş minör tonun duyurulduğu, ardından sol\# sesinin eklenmesiyle mi majör tonunun otantik kadansının kullanıldığ1 görülmektedir.

\section{1üsü Altere Edilmiş Ortak Akorun Gidilecek Tonda II. Derecenin Dominantı Olarak Kullanımı}

Tablo 4'te, gidilecek tonun VI. derecesinde bu alterasyonun 5 kez kullanıldığ1 görülmektedir. VI. derecenin 3lüsünün alterasyonu "II. derecenin dominantı" olarak adlandırılan aradominant akorudur. Bu noktada 3lünün alterasyonu ile elde edilmek istenen etkinin çoğunlukla gidilecek tona varmadan onun II. derecesini hazırlamak olduğu söylenebilir. VI. derecede 3lünün alterasyonuna örnek olarak Şekil 10'da örneklem içerisinde 026 numara olarak yer alan Johann Friedrich Reichardt'in 12 Elegies 5. Romance adlı eserinin ilk 10 ölçüsü verilmiştir. Eserin 7. ölçüsünde, do majörden fa majöre modülasyon sırasında ortak akor olarak seçilen derecenin 3lüsünün tizleştirilerek kullanıldığı görülmektedir.

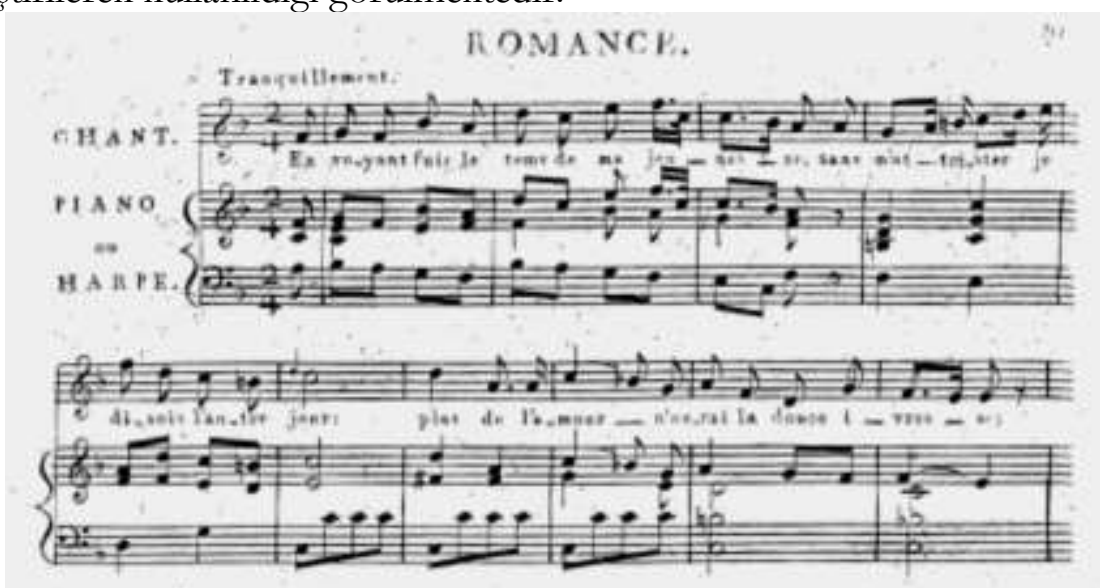

Şekil 10. VI. Derecede 3lünün Alterasyonu (Reichardt- 12 Elegies 5. Romance, 1-10. ölçüler) 
Özaltunoğlu, Ö., \& Kurtçu, G. (2021). Modülasyon sırasında alterasyonlu ortak akor kullanımının Klasik ve Romantik dönem lied örnekleminde incelenmesi. Journal of Human Sciences, 18(3), 450-472. doi:10.14687/jhs.v18i3.6172

Do majörden fa majöre modülasyon sirasinda ortak olarak kullanilan re-fa\#-la-do akoru, bulunulan tonda V. derecenin dominantı, gidilecek tonda ise II. derecenin dominantıdır. Fa majör tonuna modülasyon yapılırken, VI. derece 7 li akorunun 3lüsünün tizleştirilerek kullanılmasıyla bir anlığına da olsa Sol minör tonun duyurulduğu, ardından fa natürel sesinin eklenmesiyle Fa majör tonunun otantik kadansının kullanıldığ1 görülmektedir. 9. ölçüde eşliğin sol elinde yer alan do-si natürel-si bemol kromatik inişiyle Do major tonundan uzaklaşılmıştır.

\section{Temel Sesi Altere Edilmiş Ortak Akor Kullanımı}

Tablo 5'te, modülasyon sirasinda kullanılan ortak akorlarda "temel sesin alterasyonunu" içeren eserler; besteci isimleri, eser sayıları, modülasyondaki görevleri, eser numaraları ve altere edilmiş ortak akorun eserdeki kullanım sıklı̆̆ yazılarak gösterilmiştir.

Tablo 5. Modülasyon Sirasinda Kullanılan Ortak. Akorlarda Temel Sesin Alterasyonu

\begin{tabular}{llllll}
\hline \hline \multirow{2}{*}{ Besteci } & $\begin{array}{c}\text { Eser } \\
\text { Sayıs1 }\end{array}$ & Bulunulan Tonda Ortak Akorun Görevi & Gidilen Tonda Ortak Akorun Görevi & $\begin{array}{c}\text { Eser } \\
\text { No }\end{array}$ & $f$ \\
\hline $\begin{array}{l}\text { Johann } \\
\begin{array}{l}\text { Friedrich } \\
\text { Reichardt }\end{array}\end{array}$ & 3 & I. derece (temel sesin alterasyonu) & IV. derece (temel sesin alterasyonu) & 049 & 1 \\
\cline { 2 - 6 } & & IV. derece (temel sesin alterasyonu) & I. derece (temel sesin alterasyonu) & 075 & 1 \\
\cline { 2 - 6 } & 1 & III. derece (temel sesin alterasyonu) & IV. derece (temel sesin alterasyonu) & 085 & 1 \\
\hline $\begin{array}{l}\text { Franz } \\
\text { Schubert }\end{array}$ & 1 & VI. derece & IV. derece (temel sesin alterasyonu) & 152 & 1 \\
\hline $\begin{array}{l}\text { Johannes } \\
\text { Brahms }\end{array}$ & 1 & VI. derece & II. derece (temel sesin alterasyonu) & 174 & 1 \\
\hline $\begin{array}{l}\text { Robert } \\
\text { Franz }\end{array}$ & 6 & II. derece (temel sesin alterasyonu) & 214 & 1 \\
\hline Eser Sayis1 & & & Akor Sayls1 & 6 \\
\hline \hline
\end{tabular}

Tablo 5’te görüldüğü gibi örneklemde yer alan 231 eserin 6'sında; modülasyon sırasında kullanılan ortak akor, "temel sesi” altere edilerek kullanılmıştır. Bu alterasyonu; Johann Friedrich Reichardt'in incelenen eserlerinin 3'ünde 3 kez, Franz Schubert'in incelenen eserlerinin 1'inde 1 kez, Johannes Brahms'in incelenen eserlerinin 1'inde $1 \mathrm{kez}$, Robert Franz'in incelenen eserlerinin 1'inde 1 kez kullandığ1 görülmektedir. Bu akor; 3 eserde gidilecek tona göre; 3 eserde de hem bulunulan ton hem de gidilecek tona göre alterasyon içermektektedir.

Akorun temel sesinin altere edilmesi sonucunda, genellikle bu sesin "temel ses" görevini yitirdiği görülür. Bu alterasyonda yaygın olarak görülen durum, altere edilmiş olan temel sesin artık köksüz durumda yani temel sesi atılmış olan yeni bir akora dönüşümüdür. İncelenen eserlerin 3ünde, gidilecek tonun IV. derecesinde temel sesin altere edildiği görülmektedir. Aşağıdaki açıklamalarda temel sesi altere edilmiş ortak akorun, gidilecek tonda "dominant dominantı" ve "napoliten altılısı" olarak kullanıldığı Reichardt ve Franz'dan seçilmiş iki eser örneklenmiştir.

\section{Temel Sesi Altere Edilmiş Ortak Akorun Gidilecek Tonda Dominant Dominantı Olarak Kullanımı}

IV. derecede temel sesin alterasyonuna örnek olarak Şekil 11'de örneklem içerisinde 085 numara olarak yer alan Johann Friedrich Reichardt'ın No 53 Wandrers Nachtlied adlı eserinin ilk 8 ölçüsü verilmiştir. Eserin 6. ölçüsünde Mi bemol majör tonundan Si bemol majör tonuna modülasyon sırasında ortak akor olarak seçilen derecenin temel sesinin tizleştirilerek kullanıldığı görülmektedir.

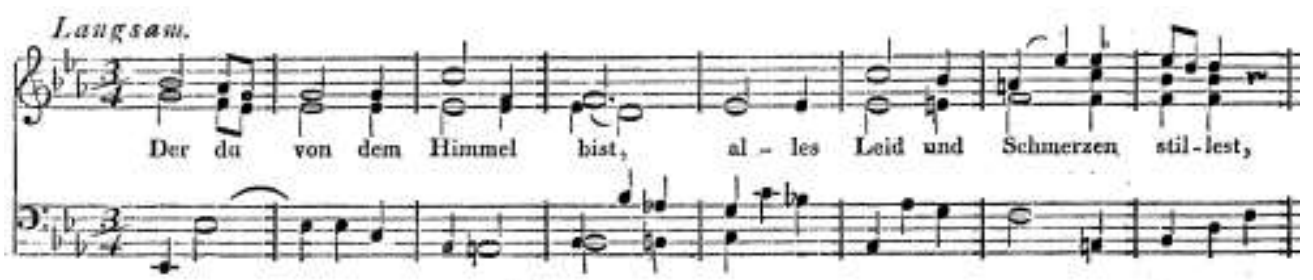

Şekil 11. IV. Derecede Temel Sesin Alterasyonu (Reichardt - No 53 Wandrers Nachtlied, 1-6. ölçüler) 
Özaltunoğlu, Ö., \& Kurtçu, G. (2021). Modülasyon sırasında alterasyonlu ortak akor kullanımının Klasik ve Romantik dönem lied örnekleminde incelenmesi. Journal of Human Sciences, 18(3), 450-472. doi:10.14687/jhs.v18i3.6172

Mib majörden Sib majöre modülasyon sırasında ortak olarak kullanılan mi natürel-sol-sib akoru, bulunulan tonda II. derecenin köksüz dominantı, gidilecek tonda ise V. derecenin köksüz dominantıdır. mib-sol-sib akorunun temel sesi altere edilmiş böylece (do)-mi natürel- sol-sib akoruna dönüşmüştür. Sib majör tonuna modülasyon yapıllırken, IV. derece akorunun temel sesi tizleştirilerek kullanılmasıyla bir anlığına da olsa Fa majör tonun duyurulduğu, ardından mib sesinin eklenmesiyle Sib majör tonunun otantik kadansının kullanıldığı görülmektedir.

\section{Temel Sesi Altere Edilmiş Ortak Akorun Gidilecek Tonda Napoliten Altılısı Olarak Kullanımı}

İncelenen eserlerin 2'sinde, gidilecek tonun II. derecesinde temel sesin altere edildiği görülmektedir. Bu noktada temel sesin alterasyonu ile gidilecek tonun napoliten altılısı kullanılmış olur. II. derecede temel sesin alterasyonuna örnek olarak Şekil 12'de örneklem içerisinde 214 numara olarak yer alan Robert Franz'in Out of My Soul's Great Sadness adlı eserinin 4-6. ölçüleri verilmiştir. Eserin 5. ölçüsünde Re minör tonundan La majör tonuna modülasyon sırasında ortak akor olarak seçilen derecenin temel sesinin pestleştirilerek kullanıldığı görülmektedir.

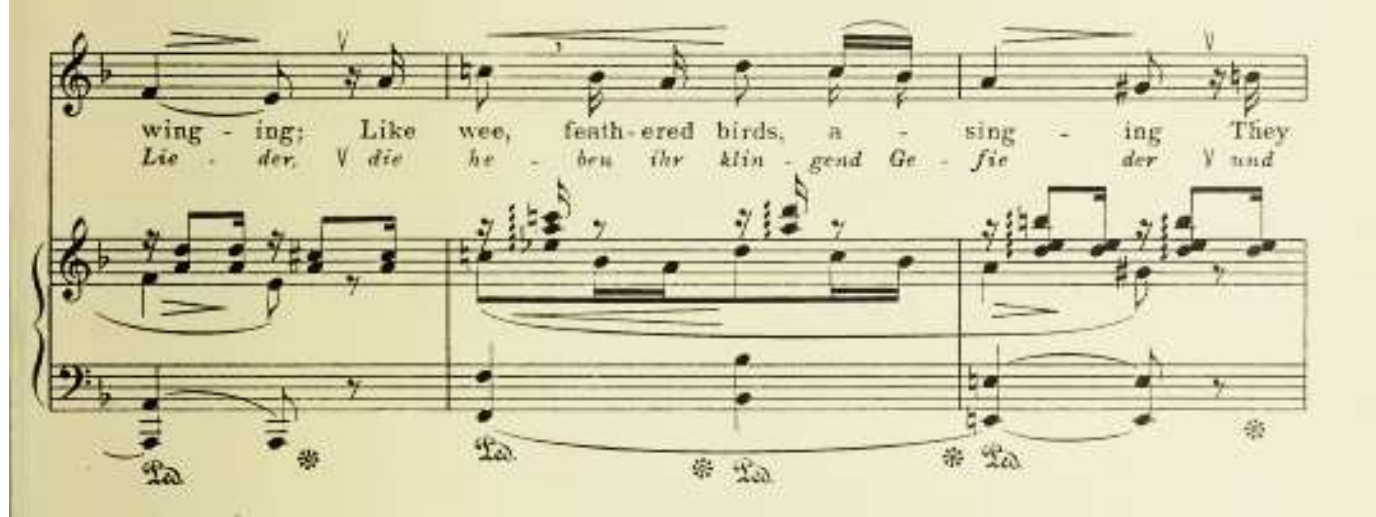

Şekil 12. II. Derecede Temel Sesin Alterasyonu (Franz - Out Of My Soul's Great Sadness, 4-6. ölçüler)

Re minörden La majöre modülasyon sırasında ortak olarak kullanılan 5lisi atılmış sib-re-la akoru, bulunulan tonda VI. derece, gidilecek tonda ise "Napoliten Altılısı"dır. Bunun yanı sira temel durumda ve 7 lisiyle birlikte kullanıldığından, akorun "Napoliten Altılısı"nın beklenen seriminin dışında istisnai bir bağlantıyla ele alındığı görülmektedir. Temel sesin bemol alarak akoru napoliten kalıbına sokması ama basta çevrim durumunun olması, altılı aralığın duyumunu engellemektedir. La majör tonuna modülasyon yapılırken, II. derece $7 \mathrm{li}$ akorunun temel sesi pestleştirilerek kullanılmasıyla bir anlığına da olsa Sib majör tonun duyurulduğu, ardından sol\# sesinin eklenmesiyle La majör tonunun otantik kadansının kullanıldığ1 görülmektedir.

\section{3lüsü ve 5lisi Altere Edilmiş Ortak Akor Kullanımı}

Tablo 6'da, modülasyon sirasinda kullanilan ortak akorlarda "3lünün ve 5linin alterasyonunu" içeren eserler; besteci isimleri, eser sayıları, modülasyondaki görevleri, eser numaraları ve altere edilmiş ortak akorun eserdeki kullanım sıklığı yazılarak gösterilmiştir.

Tablo 6. Modülasyon Sirasinda Kullanlan Ortak. Akorlarda 3 lünün ve 5linin Alterasyonu

\begin{tabular}{lcllll}
\hline \hline Besteci & $\begin{array}{c}\text { Eser } \\
\text { Sayıs }\end{array}$ & Bulunulan Tonda Ortak Akorun Görevi & Gidilen Tonda Ortak Akorun Görevi & $\begin{array}{c}\text { Eser } \\
\text { No }\end{array}$ & $f$ \\
\hline $\begin{array}{l}\text { Carl } \\
\begin{array}{l}\text { Friedrich } \\
\text { Zelter }\end{array}\end{array}$ & 2 & III. derece (3lünün ve 5linin alterasyonu) & II. derece (3lünün ve 5linin alterasyonu) & 120 & 1 \\
\cline { 3 - 6 } $\begin{array}{l}\text { Johannes } \\
\text { Brahms }\end{array}$ & 1 & VI. derece (3lünün alterasyonu) & II. derece (3lünün ve 5linin alterasyonu) & 126 & 1 \\
\hline \begin{tabular}{l} 
Eser Sayıs \\
\hline
\end{tabular} & 3 & & II. derece (3lünün ve 5linin alterasyonu) & 184 & 2 \\
\hline \hline
\end{tabular}

Tablo 6'da görüldüğü gibi örneklemde yer alan 231 eserin 3'ünde; modülasyon sırasında kullanılan ortak akor, "3lüsü ve 5lisi” altere edilerek kullanılmıştır. Bu alterasyonu; Carl Friedrich 
Özaltunoğlu, Ö., \& Kurtçu, G. (2021). Modülasyon sırasında alterasyonlu ortak akor kullanımının Klasik ve Romantik dönem lied örnekleminde incelenmesi. Journal of Human Sciences, 18(3), 450-472. doi:10.14687/jhs.v18i3.6172

Zelter'in incelenen eserlerinin 2'sinde $2 \mathrm{kez}$, Johannes Brahms'ın incelenen eserlerinin 1'inde 2 kez kullandığ1 görülmektedir. Bu akor; 1 eserde gidilecek tona göre; 2 eserde de hem bulunulan ton hem de gidilecek tona göre alterasyon içermektektedir. Besteciler modülasyonu hazırlayan ortak akordaki bu alterasyonun kullanımını sadece II. derece ile sınırlamaktadır.

Bir akorun 3lüsünün altere edilmesinin yanı sıra 5lisinin de pestleştirilmesiyle, tam 5lili yani tam uyumlu yapıdan uzaklaşılarak uyumsuz ve çözüm bekleyen eksik 5li aralı̆̆1 elde edilir. Tam tersine akorun 5lisinde kullanılan bir tizleşmeyle de yine uyumsuz ve çözüm bekleyen artmıs 5li aralığ1 elde edilir. Bu durum bestecinin, modülasyon sırasında kullandığı ortak akoru, bulunulan tonun donanımı dışında kullanmasına ve modülasyonda gidilecek ton ile ilgili oluşan fikrin ilk akorda değil, ilk akorun çözüldügü akorda oluşmasına yol açar. Bu noktada 3lü ve 5linin aynı anda alterasyonu ile elde edilmek istenen etkinin çoğunlukla gidilecek tona varmadan onun dominantı olan tonu hissettirmek olduğu söylenebilir.

II. derecede 3lünün ve 5linin alterasyonuna örnek olarak Şekil 13'te örneklem içerisinde 120 numara olarak yer alan Carl Friedrich Zelter'in Z124 No: 12 eserinin 105-127. ölçüleri verilmiştir. Eserin 114. ölçüsünde, Sib majör tonundan Do majör tonuna modülasyon sırasında ortak akor olarak seçilen derecenin 3lüsünün tizleştirilerek, bas partisinde ise 5lisinin pestleştirilerek kullanıldığ görülmektedir.

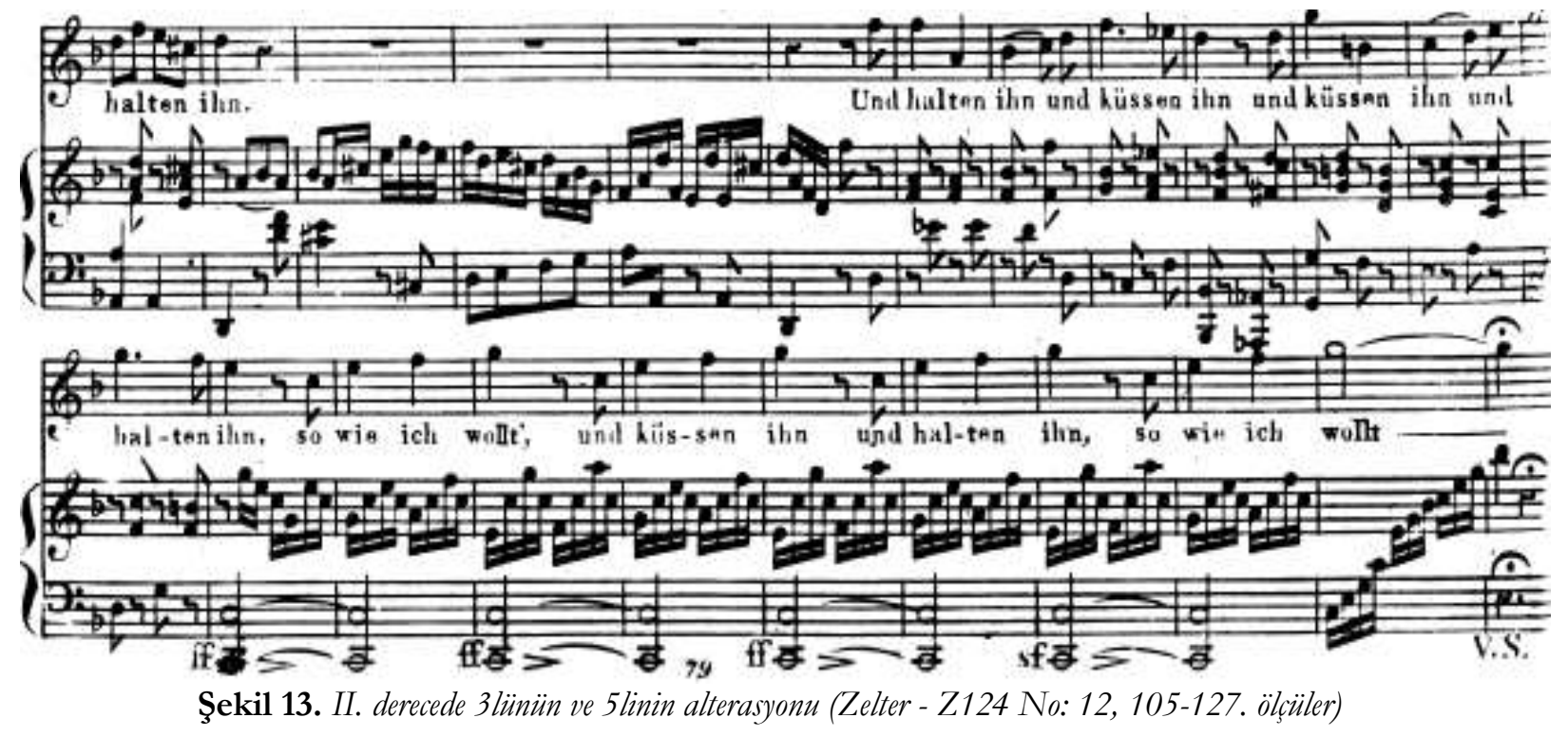

Sib majörden Do majöre modülasyon sırasında ortak olarak kullanılan re-fa\#-lab-do akoru, bulunulan tonda VI. derecenin dominant1, gidilecek tonda ise V. derecenin dominantıdır. La sesinin bemol almasıyla akorun kalıbı dominant 7li olmaktan çıkarak eksik 5lili 7li akoruna dönüşmüştür. Aynı zamanda bu akor, bas partisinde yer alan lab sesinin üzerindeki fa\# ile oluşan artmış altılı aralığıyla "Fransız Altılısı" olarak adlandırılır. Do majör tonuna modülasyon yapilırken, II. derece 7li akorunun 3lüsünün tizleştirilerek, 5lisinin pestleştirilerek kullanılmasıyla bir anlığına da olsa Sol majör tonun duyurulduğu, ardından fa natürel sesinin eklenmesiyle Do majör tonunun otantik kadansının kullanıldığı görülmektedir.

\section{7lisi Altere Edilmiş Ortak Akor Kullanımı}

Tablo 7'de, modülasyon sırasında kullanılan ortak akorlarda "7linin alterasyonunu" içeren eserler; besteci isimleri, eser sayıları, modülasyondaki görevleri, eser numaraları ve altere edilmiş ortak akorun eserdeki kullanım sıklığ1 yazılarak gösterilmiştir. 
Özaltunoğlu, Ö., \& Kurtçu, G. (2021). Modülasyon sırasında alterasyonlu ortak akor kullanımının Klasik ve Romantik dönem lied örnekleminde incelenmesi. Journal of Human Sciences, 18(3), 450-472. doi:10.14687/jhs.v18i3.6172

Tablo 7. Modülasyon Sirasinda Kullamlan Ortak. Akorlarda 7 linin Alterasyonu

\begin{tabular}{|c|c|c|c|c|c|}
\hline Besteci & $\begin{array}{l}\text { Eser } \\
\text { Say1s1 }\end{array}$ & Bulunulan Tonda Ortak Akorun Görevi & Gidilen Tonda Ortak Akorun Görevi & $\begin{array}{l}\text { Eser } \\
\text { No }\end{array}$ & $f$ \\
\hline $\begin{array}{l}\text { Wolfgang } \\
\text { Amadeus } \\
\text { Mozart }\end{array}$ & 1 & III. derece & I. derece (7linin alterasyonu) & 020 & 1 \\
\hline $\begin{array}{l}\text { Robert } \\
\text { Schumann }\end{array}$ & 1 & III. derece (7linin alterasyonu) & I. derece (7linin alterasyonu) & 164 & 1 \\
\hline $\begin{array}{l}\text { Johannes } \\
\text { Brahms }\end{array}$ & 1 & VI. derece & I. derece (7linin alterasyonu) & 205 & 1 \\
\hline Eser Sayıs1 & 3 & & & Say1s1 & 3 \\
\hline
\end{tabular}

Tablo 7'de görüldüğü gibi örneklemde yer alan 231 eserin 3'ünde; modülasyon sirasında kullanılan ortak akor, "7lisi" altere edilerek kullanılmıştır. Bu alterasyonu; Wolfgang Amadeus Mozart'in incelenen eserlerinin 1'inde $1 \mathrm{kez}$, Robert Schumann'in incelenen eserlerinin 1'inde 1 kez, Johannes Brahms'ın incelenen eserlerinin 1'inde 1 kez kullandığı görülmektedir. Bu akor; 2 eserde gidilecek tona göre; 1 eserde de hem bulunulan ton hem de gidilecek tona göre alterasyon içermektektedir. Besteciler modülasyonu hazırlayan ortak akordaki bu alterasyonu, daha çok gidilecek ton açısından ele almakta ve kullanımını sadece I. derece ile sınırlamaktadır.

I. derecenin 7 lisinin alterasyonu "subdominant dominantı" olarak adlandırılan aradominant akorudur. Bu noktada 7linin alterasyonu ile elde edilmek istenen etkinin çoğunlukla gidilecek tona varmadan onun subdominantı olan tonu hissettirmek olduğu söylenebilir. I. derecede 7linin alterasyonuna örnek olarak Şekil 14'te örneklem içerisinde 164 numara olarak yer alan Robert Schumann'ın Op.48 Dichterliebe 2. Aus Meinen Tranen Spriessen adlı eserinin 10-17. ölçüleri verilmiştir. Eserin 12. ölçüsünde Mi minör tonundan Sol majör tonuna modülasyon sırasında ortak akor olarak seçilen derecenin 7lisinin pestleştirilerek kullanıldığı görülmektedir.
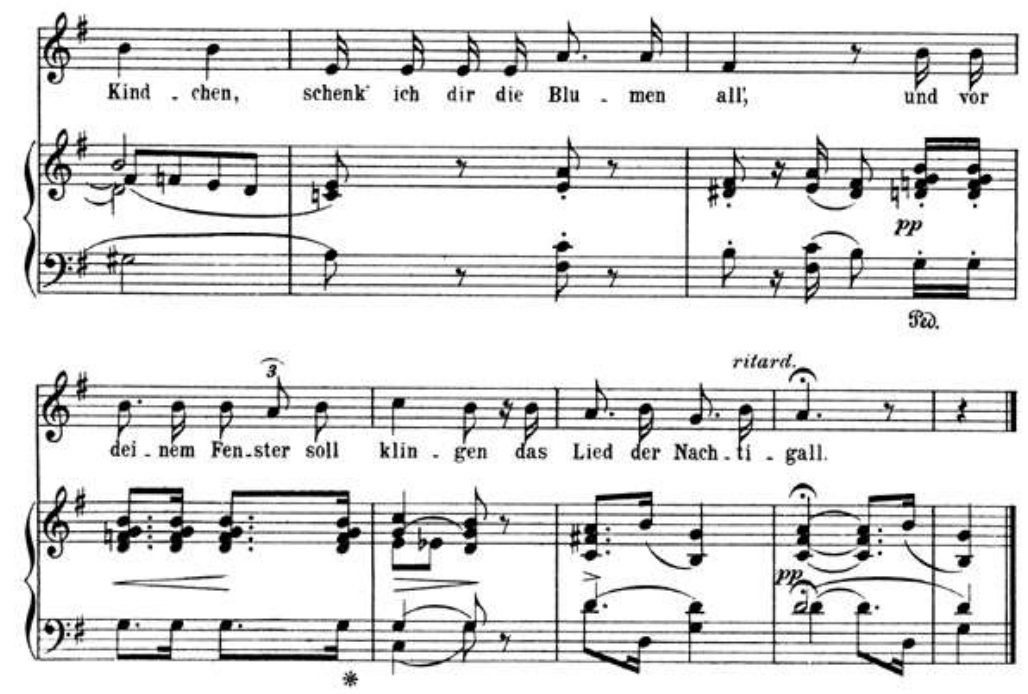

Şekil 14. I. Derecede 7linin Alterasyonu (Schumann - Op.48 Dichterliebe 2. Aus Meinen Tranen Spriessen, 10-17. ölçüler)

Mi minörden Sol majöre modülasyon sırasında ortak olarak kullanılan sol-si-re-fa natürel akoru, bulunulan tonda VI. derecenin dominantı, gidilecek tonda ise IV. derecenin dominantıdır. Sol majör tonuna modülasyon yapılırken, I. derece akorunun 7 lisinin pestleştirilerek kullanılmasıyla bir anlığına da olsa Do majör tonunun duyurulduğu, ardından fa\# sesinin eklenmesiyle Sol majör tonunun otantik kadansının kullanıldığı görülmektedir. 
Özaltunoğlu, Ö., \& Kurtçu, G. (2021). Modülasyon sırasında alterasyonlu ortak akor kullanımının Klasik ve Romantik dönem lied örnekleminde incelenmesi. Journal of Human Sciences, 18(3), 450-472. doi:10.14687/jhs.v18i3.6172

\section{5lisi Altere Edilmiş Ortak Akor Kullanımı}

Tablo 8'de, modülasyon sırasında kullanılan ortak akorlarda "5linin alterasyonunu" içeren eserler; besteci isimleri, eser sayıları, modülasyondaki görevleri, eser numaraları ve altere edilmiş ortak akorun eserdeki kullanım sıklığ1 yazılarak gösterilmiştir.

Tablo 8. Modülasyon Sirasinda Kullanılan Ortak. Akorlarda 5linin Alterasyonu

\begin{tabular}{|c|c|c|c|c|c|}
\hline Besteci & $\begin{array}{l}\text { Eser } \\
\text { Sayis1 }\end{array}$ & Bulunulan Tonda Ortak Akorun Görevi & Gidilen Tonda Ortak Akorun Görevi & $\begin{array}{l}\text { Eser } \\
\text { No }\end{array}$ & $f$ \\
\hline $\begin{array}{l}\text { Friedrich } \\
\text { Reichardt }\end{array}$ & 1 & I. derece & VI. derece (5linin alterasyonu) & 035 & 1 \\
\hline $\begin{array}{l}\text { Carl } \\
\text { Friedrich } \\
\text { Zelter }\end{array}$ & 1 & III. derece (5linin alterasyonu) & VI. derece & 130 & 1 \\
\hline Eser Say1s1 & 2 & & & Sayıs1 & 2 \\
\hline
\end{tabular}

Tablo 8'de görüldüğü gibi örneklemde yer alan 231 eserin 2'sinde; modülasyon sirasında kullanılan ortak akor, "5lisi" altere edilerek kullanılmıştır. Bu alterasyonu; Johann Friedrich Reichardt'in incelenen eserlerinin 1'inde $1 \mathrm{kez}$ ve Carl Friedrich Zelter'in incelenen eserlerinin 1 ’inde 1 kez kullandığ1 görülmektedir. Bu akor; 1 eserde gidilecek tona göre; 1 eserde de bulunulan tona göre alterasyon içermektedir.

Bulunulan tonda III. derecede 5linin alterasyonuna örnek olarak Şekil 15'te örneklem içerisinde 035 numara olarak yer alan Carl Friedrich Zelter'in Z126 NO 11 adli eserinin 12-14. ölçüleri verilmiştir. Eserin 13. ölçüsünde Mi bemol majör tonundan Si bemol minör tonuna modülasyon sırasında ortak akor olarak seçilen derecenin 5lisinin pestleştirilerek kullanıldığ1 görülmektedir.

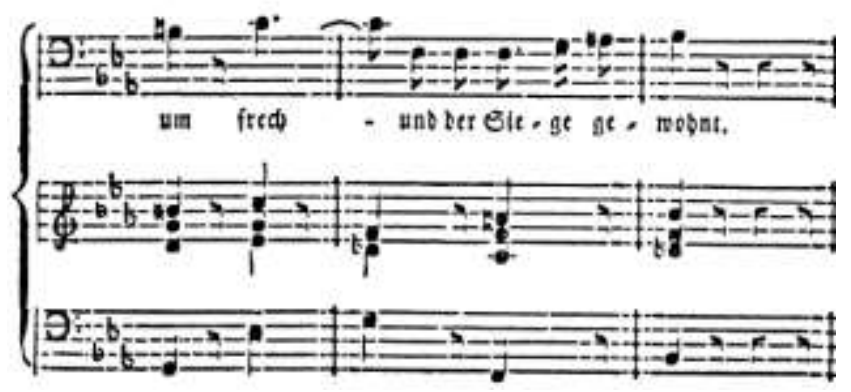

Şekil 15. III. Derecede 5linin Alterasyonu (Zelter - Z126 NO 11, 12-14. ölçüler)

Mi bemol majör tonundan Si bemol minör tonuna modülasyon sırasında ortak olarak kullanılan sol-si bemol-re bemol-fa akoru, bulunulan tonda 5lisi pestleşmiş III. derece yedili, gidilecek tonda ise VI. derece yedilidir. Si bemol minör tonuna modülasyon yapıllırken dizinin 6 . ve 7. sesinin art arda gelen akorlarda donanıma göre tizleşmesiyle çıkıcı melodik minör duyurulmuştur.

\section{Temel Sesi ve 7lisi Altere Edilmiş Ortak Akor Kullanımı}

Örneklemde yer alan 231 eserden sadece 1'inde; modülasyon sırasında kullanılan ortak akor, “temel sesi ve 7 lisi”" altere edilerek kullanılmıştır. Bu alterasyonu; Wolfgang Amadeus Mozart'ın incelenen eserlerinin 1'inde 1 kez kullandığ1 görülmektedir. Bu akor; hem bulunulan ton hem de gidilecek tona göre alterasyon içermektektedir. Mozart bu alterasyonu gidilecek tonun I. derecesinde kullanmıştır. Şekil 16'da örneklem içerisinde 013 numara olarak yer alan Wolfgang Amadeus Mozart'in das Lied der Trennung adlı eserinin 50-59. ölçüleri verilmiştir. Eserin 54. ölçüsünde Mi bemol majör tonundan La bemol majör tonuna modülasyon sırasında ortak akor olarak seçilen derecenin temel sesinin ve 7 lisinin tizleştirilerek kullanıldığı görülmektedir. 
Özaltunoğlu, Ö., \& Kurtçu, G. (2021). Modülasyon sırasında alterasyonlu ortak akor kullanımının Klasik ve Romantik dönem lied örnekleminde incelenmesi. Journal of Human Sciences, 18(3), 450-472. doi:10.14687/jhs.v18i3.6172
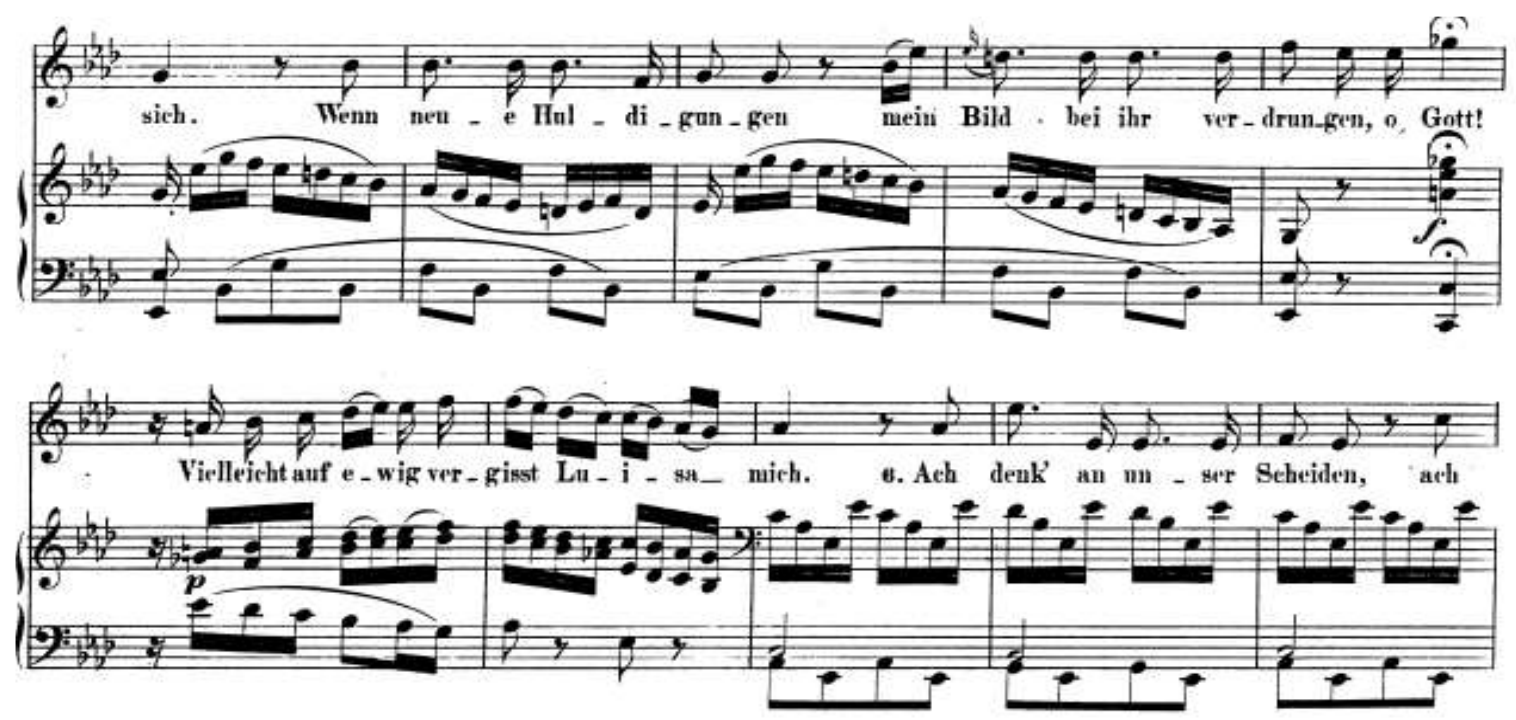

Şekil 16. I. Derecede Temel Sesin ve 7linin Alterasyonu (Mozart-Das Lied Der Trennung, 50-59. ölçüler)

Mib majörden Lab majöre modülasyon sırasında ortak olarak kullanılan la natürel-do-mibsolb akoru, bulunulan tonda V. derecenin köksüz dominant 9lusu, gidilecek tonda ise II. derecenin köksüz dominant 9lusudur. Lab majör tonuna modülasyon yapılırken, I. derece 7li akorunun temel sesinin tizleştirilerek, 7 lisinin de pestleştirilerek kullanılmasıyla bir anlığına da olsa Sib minör tonunun duyurulduğu, ardından la bemol sesinin eklenmesiyle Lab majör tonunun otantik kadansinın kullanıldığı görülmektedir.

\section{1üsü ve 91usu Altere Edilmiş Ortak Akor Kullanımı}

Örneklemde yer alan 231 eserden sadece 1'inde; modülasyon sirasında kullanilan ortak akor, “3lüsü ve 9lusu” altere edilerek kullanılmıştır. Bu alterasyonu; Robert Schumann'in incelenen eserlerinin 1'inde $1 \mathrm{kez}$ kullandığ1 görülmektedir. Bu akor; hem bulunulan ton hem de gidilecek tona göre alterasyon içermektektedir. Schumann bu alterasyonu gidilecek tonun I. derecesinde kullanmıştır. Şekil 17'de Robert Schumann'ın Op.48 Dichterliebe 2. Aus Meinen Tranen Spriessen adlı eserinin 5-12. ölçüleri verilmiştir. Eserin 10. ölçüsünde Sol majör tonundan Mi minör tonuna modülasyon sırasında ortak akor olarak seçilen derecenin gidilen tondaki tonik akoru olduğu ve bu akorun 3lüsünün tizleştirilerek, 9lusunun ise pestleştirilerek kullanıldı̆̆ı görülmektedir.
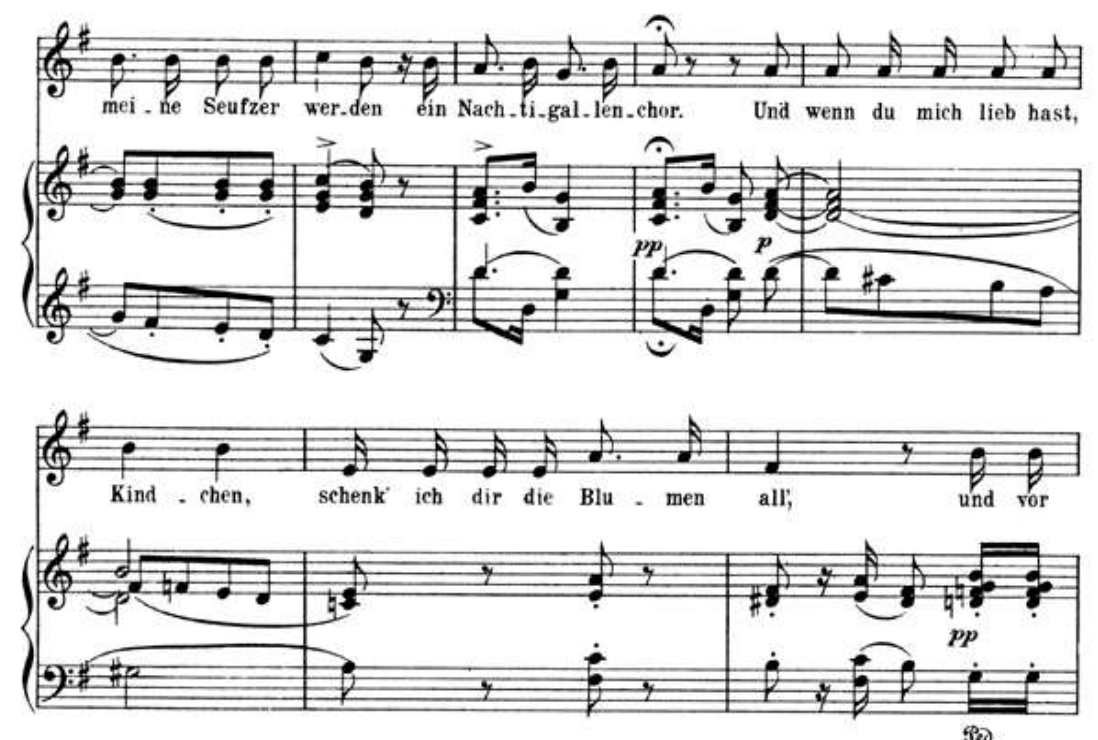

Şekil 17. I. Derecede 3lünün ve 9lunun Alterasyonu (Schumann Op.48Dicbterliebe 2. Aus Meinen Tranen Spriessen, 5-12. ölçiller) 
Özaltunoğlu, Ö., \& Kurtçu, G. (2021). Modülasyon sırasında alterasyonlu ortak akor kullanımının Klasik ve Romantik dönem lied örnekleminde incelenmesi. Journal of Human Sciences, 18(3), 450-472. doi:10.14687/jhs.v18i3.6172

Sol majörden Mi minöre modülasyon sırasında ortak olarak kullanılan mi-sol\#-si- re-fa natürel akoru, bulunulan tonda II. derecenin dominant1, gidilecek tonda ise IV. derecenin dominantıdır. Mi minör tonuna modülasyon yapılırken, I. derece akorunun 3lüsünün tizleştirilerek, 9lusunun pestleştirilerek kullanılmasıyla bir anlığına da olsa la minör tonunun duyurulduğu, ardından fa\# sesinin eklenmesiyle Mi minör tonunun II. derecesinin kullanıldığı görülmektedir.

\section{Sonuç, Tartışma ve Öneriler}

Modülasyonda altere edilmiş ortak akor kullanımının, Klasik ve Romantik dönem bestecileri açısından ne düzeyde çeşitlendiğinin sorgulandığı bu araştırmada; 231 lied incelenmiş ve bu eserlerde 64 tane altere edilmiş ortak akor olduğu tespit edilmiştir. Modülasyon sırasında bestecilerin genellikle altere edilmemiş ortak akor kullanmayı tercih ettiği görülmektedir. Eserlerde tonalitenin değişimi genellikle gidilecek tonun II, IV ya da VI. derecelerinin ortak akor olarak seçilmesiyle gerçekleşmekte; bu durum modülasyon yapılan tonun daha anlaşılır olmasını sağlamaktadır.

Modülasyon sırasında alterasyon kullanımıyla; bulunulan ton kısa süreliğine belirsizleşmekte, sanki başka bir tona modülasyon yapılacakmış düşüncesi oluşmaktadır. Minör bir akorun 3lüsünün tizleştirilip bir başka tonun dominant akorunun elde edilmesine ya da majör bir akorun 3lüsünün pestleştirilip adaş tonlar arasında ödünç akorlar kullanılabilmesine olanak sağlayan 3lünün alterasyonu, hem Klasik hem de Romantik dönemde en kullanışlı araç olarak karşımıza çıkmaktadır. Bu aracın ton içerisindeki görevine bakıldığında ise "gidilecek tonun II. derecesi" olarak kullanımı ön plandadır. II. derece akorundaki bu değişim, modülasyona "dominant dominantı" akoru ile giriş yapma anlamında Reichardt, Zelter, Schumann, Brahms, Franz ve Jensen tarafından sıklıkla kullanılmıştır. Beethoven, Mozart ve Schubert ise 3lünün alterasyonunu modülasyon sirasında gidilecek tonun II. derecesinde değil de I, III, IV ya da VI. derecelerinde kullanmaktadırlar. I. derecede 3lünün alterasyonu minör tonda "subdominant dominantı", III. derecede 3lünün alterasyonu majör tonda "VI. derecenin dominantı", IV. derecede 3lünün alterasyonu "minör/majör subdominant", VI. derecede 3lünün alterasyonu ise "II. derecenin dominantı" göreviyle karşımıza çıkmaktadır.

Akorun temel sesinin altere edilmesi, napoliten altılısına ya da köksüz durumda yeni bir akora dönüşmesine yol açar. Bu yeni akorun modülasyon sırasındaki kullanımına bakıldığında gidilecek tonun I, II ya da IV. derece akoru olarak tasarlandığ1 görülür. Brahms ve Franz bu alterasyonu sadece gidilecek tonun "napoliten altıllssı" olarak II. derecenin altere edilmiş temel sesiyle kullanmıştır. Schubert gidilecek tonun IV. derecesinde bu alterasyonu kullanarak "dominant dominatı" akoru ile modülasyona giriş yapmakta; Reichardt ise bu alterasyonu hem IV. derecede hem de I. derecede kullanarak "dominant dominantı" ve "II. derecenin dominantı"nı modülasyona başlama aracı olarak değerlendirmektedir.

3lüsü ve 5lisi altere edilmiş ortak akor kullanılarak yapılan modülasyon örneklerinde Zelter ve Brahms öne çıkmaktadır. Her iki besteci de bu alterasyonla gidilecek tonun II. derece akorunu "beşlisi pestleşmiş dominant dominantı" akoruna dönüştürerek kullanmaktadır. 3lünün alterasyonunda oluşan "dominant dominantı" akorunun kullanımına göre 3lü ve 5linin alterasyonuyla elde edilen eksik 5lili “dominant dominantı"nın oldukça az sayıda kullanıldığı görülmektedir.

7 linin alterasyonu gidilecek majör tonda I. derece akorunda Mozart, Schumann ve Brahms tarafindan sadece birer kez kullanılmıştır. I. derecede 7linin alterasyonu kullanılarak, bu üç eserde modülasyona "subdominant dominantı" akoru ile giriş yapılmıştır.

5linin alterasyonu Reichardt tarafindan gidilecek tonda VI. derecede bir kez, Zelter tarafindan da bulunulan tonda III. derecede bir kez kullanılmıştır. Bu alterasyon akorun tam 5lili yani tam uyumlu yapısının bozulmasıyla oluşan, gergin ve çözüm bekleyen eksik 5li ya da artmış 5linin kullanımı şeklinde karşımıza çıkmaktadır. 
Özaltunoğlu, Ö., \& Kurtçu, G. (2021). Modülasyon sırasında alterasyonlu ortak akor kullanımının Klasik ve Romantik dönem lied örnekleminde incelenmesi. Journal of Human Sciences, 18(3), 450-472. doi:10.14687/jhs.v18i3.6172

Temel sesin ve 7linin alterasyonuyla kullanılan ortak akor örneği Mozart’’n bir eserinde karşımıza çıkmaktadır. Gidilecek tonda tonik akorunun temel sesi tizleştirilirken 7lisi de pestleştirilerek kullanılmış böylece "II. derecenin köksüz dominant dokuzlusu” elde edilmiştir.

3lünün ve 9lunun alterasyonu da sadece bir eserde görülmüştür. Schumann bu alterasyonu gidilecek tonun tonik akorunda kullanmış, böylece tonik akoru "subdominant dominantı"na dönüşmüştür. Bu modülasyonda öncelikle gidilecek tonun ilgili subdominant tonuna karar verme etkisi hissedilmekte, ardından modülasyon tamamlanmaktadır.

Bestecilerin, eserlerindeki altere edilmiş ortak akor çeşitliliği bakımından karşılaştırılması sonucunda, üç bestecinin bu konuda farklılaştığ1 görülmüştür. Brahms modülasyona başlarken kullandığı ortak akoru; gidilecek tonda II. derecenin 3lüsünü altere ederek "dominant dominantı", temel sesini altere ederek "napoliten altılı", 3lü ve 5lisini altere ederek "5lisi pestleşmiş dominant dominantı", I. derecenin 7 lisini altere ederek "subdominant dominantı" olmak üzere dört farklı şekilde kullanmaktadır. Böylece modülasyonun bir alterasyon aracilığıyla gerçekleştiği noktada Brahms, gidilecek tonu bir anlığına belirsizleştirme açısından daha zengin bir kullanım ortaya koymaktadır.

Beethoven ve Jensen'in incelenen eserlerinde ise sadece 3lüsü altere edilmiş ortak akora yer verdikleri görülmüştür. Jensen iki eserde, modülasyona başlarken gidilecek tonda 3lüsü altere edilmiş II. derece yani "dominant dominantı" akorunu kullanmıştır. Beethoven incelenen bir eserinde, gidilecek tonun IV. derecesini 3lünün alterasyonuyla kullanmış, böylece "minör subdominant" akoruyla modülasyona başlamıştır. Başka bir eserinde Beethoven, gidilecek tonun VI. derecesinde akorun 3lüsünü altere ederek "II. derecenin dominantı" akoruna dönüştürmüştür. Burada görülmesi gereken Beethoven ve Jensen'in modülasyon için kullanılan ortak akorda az sayıda alterasyon kullanarak, dolaylı bir yol izlemeden, gidilecek tonu belirgin bir şekilde ortaya koyma eğilimi içerisinde olduklarıdır.

Romantik dönem bestecilerinin Klasik döneme göre daha fazla altere edilmiş ortak akorla modülasyon yapacağı öngörüsünde hazırlanan bu çalışmada; incelenen eserlerin içerdiği ortak akoru ilgilendiren yedi farklı alterasyondan hemen hepsinde dönemler açısından belirgin bir farklılık görülmemektedir. Klasik ve Romantik dönemden seçilmiş bu eserlerde ortak akorla ilgili alterasyonların eşit oranda dağılımı söz konusudur. Klasik dönemden seçilmiş eserlerde hiç kullanılmadığ1 görülen "3lünün ve 9lunun" alterasyonuna, Romantik dönemde sadece birer eserde bir kez yer verilmiştir. Aynı şekilde Romantik dönemde hiç kullanılmadığ1 görülen "5linin" alterasyonuna Klasik dönemde iki kez, "temel sesin ve 7linin" alterasyonuna da bir kez yer verilmiştir. Bir alterasyonun 231 eserde bir ya da iki kere kullanılması, dönemler açısından belirgin bir fark olduğunu söylemekte yetersiz kalmaktadır.

Müzik teorisi eğitiminde yerleşmiş olan bilgi birikiminin sağlamasının yapılması adına bu ve benzeri çalışmalara ihtiyaç olduğu açıktır. Alterasyonların sadece modülasyon sırasındaki kullanımıyla sınırlandırılmış olan bu çalısmanın sonuçları, modülasyon dışında kullanılan alterasyonların farklı dönemlerden, farklı bestecilerin eserlerinin inceleneceği çalışma sonuçlarıyla karşılaştırılmalıdır.

\section{Kaynakça}

Cangal, N. (2010), Armoni. Ankara: Arkadaş Yayınevi.

Cangal, N. (2010). Mürik Formlar (3. Basım). Ankara: Arkadaş Yayınevi.

Cutter, B. (1902). Harmonic Analysis. Boston: Oliver Ditson Company.

Çelebioğlu, E. (1986). Taribsel Açıdan Evrensel Müriğge Giriș. İstanbul: Tasvir Matbaası.

Çelebioğlu, E. (2013). Armoni. İstanbul: Pan Yayincillk.

David, H. T. (1956). Mozartean Modulations. The Musical Quarterly, 42 (2), 193-212, Oxford University Press

Grove, G. (1880). A Dictionary of Music and Musician Volume II. London: Macmillan and co.

Hubbard, W. L. (1930). The Imperial History and Encyclopedia of Music, Musical Dictionary. New York: T. J. Ford \& co. 
Özaltunoğlu, Ö., \& Kurtçu, G. (2021). Modülasyon sırasında alterasyonlu ortak akor kullanımının Klasik ve Romantik dönem lied örnekleminde incelenmesi. Journal of Human Sciences, 18(3), 450-472. doi:10.14687/jhs.v18i3.6172

Hubbard, W. L. (1930). The Imperial History and Encyclopedia of Music, Theory of Music. New York: T. J. Ford \& co.

Kitson, C. H. (1914). The Evolution of Harmony. London: Oxford University Press.

Korsakof, N. R. (1996), Kuramsal ve Uygulamal Armoni (Çev: Ahmet Muhtar Ataman). İzmir: Şahsi Basim.

Özaltunoğlu, Ö. (2016). Dört Partili Akor Bağlantılaryla Dikte. Ankara: Gece Kitaplığ1.

Özdemir, M. (2001). Armoni. İzmir: Kany1lmaz Matbaacilik.

Rougnon, P. (1930). Mufassal Musiki Naz̧ariyatı (Çev: Ahmet Muhtar Ataman). İstanbul: Devlet Matbaas1

Tutu, T. (1986). Cö̋zümlemeli Armoni. İzmir: Müzik Eserleri Yayınları.

Thompson, W. F. ve Cuddy, L. L. (1989). Sensitivity to Key Change in Chorale Sequences: A Comparison of Single Voices and Four-Voice Harmony. Music Perception: An Interdisciplinary Journal, 7 (2), 151-168, University of California Press.

Werts, D. (1983). A Theory of Scale Reference. Unpublished Doctoral Dissertation, Department of Music, Princeton University, Princeton.

\section{Extended English Summary}

In this research, in which the use of common chords altered during modulation has been questioned in terms of composers of Classical and Romantic periods; 231 lieds were examined and 64 altered common chords were found in these works. It is observed that composers generally prefer to use unaltered common chords during modulation. It is realized; the change of tonality in the works is usually by choosing the IInd, IVth or VIth degrees of the destination key as common chord, this makes the destination key more understandable.

With the use of alteration during modulation; the destination key becomes uncertain for a short time, as if the modulation will be made to another key. In the lieds examined within the scope of the study, it was observed that most of the 3rd of the common chords used during modulation were altered. This alteration, which allows the 3 rd of a minor chord to be raised and the dominant chord of another to be obtained, or the third of a major chord to be lowered up and the use of borrowed chords among the enharmonic keys, is the most useful tool in both the Classical and Romantic periods. When we look at the role of this tool in key, it is "IInd degree of destination key" in the foreground. This change in IInd degree chord has been frequently used by Reichardt, Zelter, Schumann, Brahms, Franz and Jensen to mean entering modulation with the "secondary dominant" chord. Beethoven, Mozart and Schubert, on the other hand, change the alteration of the 3rd during modulation, not in the IInd degree but they use it in Ist, IIIrd, IVth or VIth. degrees. The alteration of the $3 \mathrm{rd}$ in the Ist degree is "dominant chord of subdominant " in the minor key, the alteration of the 3rd in the IIIrd degree is "dominant chord of VIth" in the major key, the alteration of the 3rd in the IVth degree is "minor/major subdominant", and the alteration of the 3rd in the VIth degree is "dominant chord of IInd" appears before us with the task.

Altering the 1 st of the chord causes it to become a Neapolitan sixth or a new chord in the rootless state. Considering the use of this new chord during modulation, it is seen that it was designed as a Ist, IInd or IVth degree of the destination key. Brahms and Franz named this alteration only as the "Neapolitan six" of the destination key with the altered 1st of the chord. Schubert is by using this alteration in the IVth degree, it enters the modulation with the "secondary dominant"; Reichardt, on the other hand, using this alteration both IVth and the Ist degree as the "secondary dominant" and "dominant chord of IInd" as a means of starting modulation.

Zelter and Brahms stand out in the examples of modulation using common chords altered in 3rd and 5th. Both composers use the IInd degree of destination key with this alteration by transforming it into the "lowered 5th secondary dominant" chord. 
The alteration of the 7th was used only once by Mozart, Schumann and Brahms in the Ist degree in the destination major key. By using the 7th alteration in the Ist degree, these three works have entered the modulation with the " dominant chord of subdominant".

The alteration of 5 th is in VIth degree of destination key by Reichardt once, in IIIrd degree of destination key by Zelter once also found used. This alteration appears in the form of the use of tense and awaiting raised 5th or lowered 5th, which are formed by the disruption of the fully compatible structure of the chord.

An example of a common chord used with the alteration of the 1st and the 7th appears in a work of Mozart. While the 1st of the tonic chord was raised, the 7th was used by lowered in the destination key, thus "the rootless dominant 9th of II. degree" was obtained.

The alteration of the 3rd and 9th was also seen in only one work. Schumann used this alteration in the tonic chord of the destination key, thus the tonic chord has turned into a " dominant chord of subdominant". In this modulation, first of all, the effect of deciding on the subdominant of the key to be visited is felt, and then the modulation is completed.

As a result of the comparison of the composers in terms of the variety of common chords in their works, it was seen that the three composers differed in this regard. The common chord he uses when starting Brahms modulation; IInd degree of the destination key as "secondary dominant" by altering the $3 \mathrm{rd}$, as "neapolitan sixth" by altering the 1st, as "secondary dominant with lowered 5th" by altering the 3rd and 5th, tonic of the destination key as "dominant chord of subdominant" by altering the $7 \mathrm{th}$, is used in four different ways. Thus, at the point where the modulation takes place through an alteration, Brahms offers a richer use in terms of obscuring the destination key for a moment.

It was seen that Beethoven and Jensen used common chords, of which only 3rd were altered, in their studied works. In two works of Jensen was used the "secondary dominant" chord in the destination key when starting modulation. In one of his work Beethoven used IVth degree of the destination key with the alteration of $3 \mathrm{rd}$, so he started modulation with the "minor subdominant" chord. In another work Beethoven, by altering the 3rd of the VIth degree of destination key, has turned it into a "dominant chord of IInd degree". What should be seen here is that Beethoven and Jensen tend to clearly express the destination key without following an indirect path, using a small number of alterations in the common chord used for modulation.

In this study, which was prepared with the prediction that Romantic period composers will modulate with the common chord, which is more altered than the Classical period; there is no significant difference in terms of periods in almost all of the eight different alterations that concern the common chord included in the studied works. In these works, selected from the Classical and Romantic periods, there is an equal distribution of alterations related to the common chord. In the Romantic period, the alteration of the "3rd and 9th", which were never used in selected works from the classical period, were included only once in each work. Likewise, the alteration of the "5th", which was never used in the Romantic period, was included twice in the Classical period, and the alteration of the "1st and 7th" once. The use of an alteration once or twice in 231 works is insufficient to say that there is a significant difference in terms of periods.

It is clear that this and similar studies are needed in order to provide the knowledge established in music theory education. The results of this study, which is limited to the use of alterations only during modulation, should be compared with the results of the study in which the works of different composers from different periods of alterations used outside of modulation will be examined. 